\title{
THE SHORT TERM IMPACT OF A PRODUCTIVE ASSET TRANSFER IN FAMILIES WITH CHILD LABOR: EXPERIMENTAL EVIDENCE FROM THE PHILIPPINES
}

\author{
Eric V. Edmonds \\ Caroline B. Theoharides \\ Working Paper 26190 \\ http://www.nber.org/papers/w26190 \\ NATIONAL BUREAU OF ECONOMIC RESEARCH \\ 1050 Massachusetts Avenue \\ Cambridge, MA 02138 \\ August 2019
}

Funding for this research was provided by the United States Department of Labor under Cooperative Agreement IL-27208. This study does not reflect the views or policies of the United States Department of Labor nor does the mention of trade names, commercial products, or organizations imply endorsement by the United States Government. The views expressed herein are those of the authors and do not necessarily reflect the views of the National Bureau of Economic Research.

NBER working papers are circulated for discussion and comment purposes. They have not been peer-reviewed or been subject to the review by the NBER Board of Directors that accompanies official NBER publications.

(C) 2019 by Eric V. Edmonds and Caroline B. Theoharides. All rights reserved. Short sections of text, not to exceed two paragraphs, may be quoted without explicit permission provided that full credit, including $\odot$ notice, is given to the source. 
The Short Term Impact of a Productive Asset Transfer in Families with Child Labor:

Experimental Evidence from the Philippines

Eric V. Edmonds and Caroline B. Theoharides

NBER Working Paper No. 26190

August 2019

JEL No. J22,L26,O15

\begin{abstract}
Productive asset grants have become an important tool in efforts to push the very poor out of poverty, but they require labor to convert the asset into income. Using a clustered randomized trial, we work with the Government of the Philippines to evaluate a key component of their child labor elimination program, a $\$ 518$ productive asset grant directed at families with child laborers. Treatment increases household based economic activity. Household well-being improves, mainly through increases in food security and child welfare. Households achieve these improvements in well-being by drawing upon the labor of household members. Adolescent labor is the most available labor, and we observe increases in employment among adolescents not engaged in child labor at baseline. Households with a family firm or business prior to treatment especially lack available adult labor to work with the asset leading to increases in child labor, including hazardous work, amongst children who were not in child labor at baseline.
\end{abstract}

Eric V. Edmonds

Department of Economics

Dartmouth College

6106 Rockefeller Hall

Hanover, NH 03755

and NBER

Eric.V.Edmonds@Dartmouth.edu

Caroline B. Theoharides

Amherst College

ctheoharides@amherst.edu

A randomized controlled trials registry entry is available at https://www.socialscienceregistry.org/trials/1139

Supporting Materials are available at

https://sites.dartmouth.edu/eedmonds/kasama/

Online appendices are available at

https://www.nber.org/data-appendix/w26190/ 


\section{Introduction}

Large, one-time transfers to poor families are a fundamental piece of the anti-poverty toolkit. Several studies document that these large, one time transfers to poor families result in households starting or expanding household based economic activity with meaningful impacts on the consumption and health of family members. Can such programs disrupt the intergenerational transmission of poverty? The impact of such programs on the next generation depends on the survival of the wealth generated by the asset and the impact of such transfers on human capital investments.

For adolescents in settings with complete labor markets (in the sense that the household is a price taker in the labor market), the primary impact of the introduction of a productive asset depends on the wealth effect of the transfer which, if positive, should promote human capital through schooling, free time, and mental health. However, in the presence of multiple factor market failures, the introduction or expansion of a productive asset could increase the value of child time, resulting in increases in child labor (Basu, Das and Dutta, 2010). Given the recent evidence against the completeness of factor markets (LaFave and Thomas, 2016) especially among the poorest (LaFave, Peet and Thomas, 2017), it is important to understand the implications of these livelihood promotion projects on adolescents since such programs now play a central role in global efforts to combat both poverty and child labor.

This study examines the effects of an asset transfer on adolescents and their families in settings where child labor is prevalent using experimental variation in a livelihood promotion project in the Philippines. Kabuhayan Para sa Magulang ng Batang Manggagawa (KASAMA) is an important piece of the Government of the Philippines effort to eliminate child labor, and for this study, the Philippine Department of Labor and Employment (DOLE) partnered with the authors in an evaluation of KASAMA across 164 communities and 2,296 households where child labor is prevalent. KASAMA provides a one-time USD $\$ 518$ in-kind asset transfer (selected by the beneficiary) and 3 days of training related to operating a business and child labor. For comparison, average per capita expenditure of beneficiaries in the study population is USD $\$ 1.30$ per day, and the most common forms of child labor are in agriculture, retail, and domestic service. The impact evaluation of KASAMA took place between August 2015 and September 2018.

The theory behind KASAMA is that this one-time transfer expands the presence of productive assets in the family and pushes households to a level of wealth where they are capable of sustaining and growing their income, eliminating motives for child labor. Thus, we examine whether KASAMA 
has an effect on how the household generates its livelihood, whether there is an effect on household living standards and adolescent well-being, and whether it changes child labor in the household.

We find that in response to the KASAMA treatment, households are more likely to report a family firm and household based economic activity increases. Household well-being also improves, mainly through increases in food security and child welfare. In aggregate, we cannot reject the null hypothesis that there is no change in overall economic activity among adolescents in our sample.

However, this aggregate masks important heterogeneity. ${ }^{1}$ The intervention is targeted at households with a child laborer present, but not all children in our households are in child labor at baseline. Treatment has negligible influence on the labor supply of adolescents in child labor at baseline, but we observe increases in economic activity for those children not in child labor at baseline. This increase in working children is especially large in magnitude in families with a nonfarm business at baseline. Available labor is scarcest in those families, and we observe increases in child labor, even hazardous child labor, with treatment, and we cannot reject the null of no effect of treatment on child well-being for these children.

Our findings provide further evidence on the effects of asset transfers on beneficiary families, contributing to a large, growing literature (De Mel, McKenzie and Woodruff, 2008, Blattman, Fiala and Martinez, 2013; Karlan, Knight and Udry, 2015; Blattman and Dercon, 2016; Haushofer and Shapiro, 2016). Our focus on child related outcomes and on interviewing adolescents directly provides a novel perspective that has not drawn attention in studies of similar one time, large transfer programs. Because of their ability to substitute for adults in a variety of tasks, adolescents may be particularly vulnerable to bearing some of the costs of an asset transfer if such a transfer impacts the household in more ways than just the wealth effect, and policymakers may be interested in effects on adolescents as they are unlikely to have complete agency over their own time allocation. Our principal finding, that households draw on available labor to work the productive asset, implies that attention to the impact of asset transfers on adolescents is appropriate anywhere adolescents make up a substantive part of available labor.

Our findings also help address the question of how productive assets impact child labor. Because the child labor policy community views productive asset transfers as critical in their efforts to decrease child labor, several studies grapple with understanding the relationship between household

\footnotetext{
${ }^{1}$ Our analysis plan pre-specified looking at heterogeneity in treatment based on whether a child was in child labor at baseline based on the literature's finding that it is easier to prevent a child from starting work than to get a working child to stop. Our pre-analysis plan did not specify looking at heterogeneity based on the presence of a nonfarm business at baseline; this was suggested by a reviewer at the pre-results stage (stage 1), after our pre-analysis plan but before we analyzed the endline data.
} 
asset wealth and child time allocation (Bhalotra and Heady, 2003, Cockburn and Dostie, 2007, Basu, Das and Dutta, 2010, Dumas, 2013). This literature has struggled to address why households differ in their asset wealth. The experimental variation in KASAMA allows us to separate out the role productive assets play in child labor from other factors such as local labor market conditions and family histories that are apt to be correlated with household asset endowments. Our findings are consistent with non-separability of household production and consumption decisions, implying that households with more productive assets differ in both wealth and the value of child time (Singh, Squire and Strauss, 1986). Hence, the net effect of productive assets on child labor depends on whether the wealth effect or the change in the value of time dominates. In our setting, there appears to be little change in time allocation among children already in child labor at baseline. The dominant change (increase) in employment comes from those not in child labor at baseline.

Finally, our findings are relevant to the literature studying ultra-poor graduation programs (UPGs) (Banerjee et al., 2015). In one of our stratum, all of our subjects (treatment and control) receive the government's Pantawid Pamilyang Pilipino Program (4Ps). Hence the impact of KASAMA calculated within the stratum has the interpretation of providing KASAMA on top of 4Ps. 4Ps provides consumption support, health insurance, preventative health care, life skills coaching, job skills coaching, and financial access. 4Ps + KASAMA is not a UPG although it has lot in common with the space of programs covered under the UPG moniker. ${ }^{2}$ Unpacking and understanding how UPGs work is an important, on-going research topic, and our study is closely related to Banerjee et al. (2018) which evaluates the impact of giving recipients 4 goats without consumption support. In our 4Ps stratum, we are evaluating the impact of a productive asset transfer on top of consumption support and the other components of $4 \mathrm{Ps}$. We find that treatment leads to larger increases in child employment in our 4Ps stratum, including in activities that would be considered hazardous child labor. A close examination of the data reveals that this larger increase in child employment with treatment is feasible, because the 4 Ps stratum has more available labor to work the asset at baseline. Hence, we repeatedly observe throughout our findings that households draw on available household labor to work the productive asset.

\footnotetext{
${ }^{2}$ The UPG space encompasses a wide variety of programs, but there are some clear ways in which the KASAMA +4 Ps context differs. Most UPGs have some forced savings component which our subjects do not. All UPGs have some market research conducted that leads to the choice of productive asset. Our subjects choose their productive asset. All UPGs have home visits for life skills coaching whereas those sessions are held in community meetings under 4Ps. The on-going UPG evaluation in the Philippines uses DILEEP (the non-child labor version of KASAMA) and $4 \mathrm{Ps}$.
} 


\section{Background}

\subsection{Intervention}

The Government of the Philippines is committed to eliminating child labor, with the target of reducing the number of child labors by 600,000 in the most recent National Development Plan. DOLE's Child Labor Prevention and Elimination Program (CLPEP) plays a leading role in efforts to meet this target, and the most resource intensive component of CLPEP is KASAMA, the focus of this evaluation.

Principally, KASAMA is a large, one time transfer of PHP10,000 (USD $\$ 518$ in PPP terms, USD $\$ 184$ in nominal terms) to a family with child laborers present. Local governments maintain registries of poor families and families where child labor illegal under Philippine law is known to exist in each locality. ${ }^{3}$ The intersection of these two lists are potential KASAMA beneficiaries. The transfer is made in-kind rather than in cash. Either DOLE or a subcontractor work with beneficiaries to identify the type(s) of productive assets that the beneficiary wants, and those assets are provided to the beneficiary.

Distributed KASAMA benefits in our treatment group are largely for petty trading. Table 1 tabulates the distributed benefits using DOLE's official records. Because households are free to sell their assets after distribution, Table 1 is not necessarily informative about what's become of the KASAMA assets at the time of endline. 70 percent of distributed assets go into rice and food trading or stocking a sari-sari, or variety, store. Six percent go to support fishing, four percent to farming, and the remainder that can be classified go to tools or inputs into skilled trades.

In addition to the asset transfer, beneficiaries are asked to attend 3 one-day trainings. DOLE believes that the trainings are important in making the asset transfer successful. These trainings provide assistance on developing a business plan (which leads to the selection of the asset during the training day), some education on bookkeeping, marketing and financial literacy, and an orientation on child labor. The child labor orientation is a description of how child labor is defined legally in the Philippines and how the government is engaging communities to reduce child labor. It is not specific to KASAMA and, unlike many child labor trainings in other countries, it is not oriented towards changing household assessments of the the health and safety risks of work. KASAMA was implemented in our study areas by DOLE following their usual operating procedures. Hence, the procurement and distribution of assets, all trainings, and all monitoring and audits were imple-

\footnotetext{
${ }^{3}$ See On-line Appendix 2.3 for details on the Philippine legal definition of child labor.
} 
mented following DOLE's standard way of implementing KASAMA. Appendix 1 provides detail on DOLE's implementation process.

The policy context for KASAMA is important to understanding the treatment. All of our study population should be receiving the Pantawid Pamilyang Pilipino Program (4Ps). The 4Ps program is a cash transfer program that provides poor families with children with consumption support, health insurance, preventative health care, life skills coaching, job skills coaching, and financial access. 4Ps benefits are paid every two months to a bank account accessible via a cash card. Benefits increase in the number of children to a maximum of 3 and vary with the age of the child. In most writings, 4Ps is described as a conditional cash transfer, because recipients agree ex-ante to pre and post natal visits, pre-school, and schooling, but the program director informed the authors in a personal interview in October 2016 that he was not aware of any beneficiaries ever having benefits terminated because of non-compliance with those conditions. Rollout of 4Ps across communities began in 2008 and should have been fully rolled out in our study area as of $2014 .^{4}$ Hence, there should have been plenty of time for households in our study area to learn about the lack of enforcement of the conditionality.

Our evaluation of KASAMA takes place in 164 communities (legally, barangays) in Regions I, II, III, IV-A, and V on the island of Luzon. ${ }^{5}$ In all communities, DOLE has not previously undertaken projects to address child labor. ${ }^{6}$ Communities were grouped into 4 strata by researchers (urban v. rural * complete 4Ps v. incomplete), and a random number generator was used by the research team to allocate communities to treatment and control status. 82 communities were assigned to treatment.

While randomization takes place at the community level, KASAMA benefits are distributed to households with child labor present. DOLE identified at least 14 eligible households from each of

\footnotetext{
${ }^{4}$ While all of our study communities should have had 4Ps fully implemented as of 2014, not all subjects report receiving 4 Ps. They all should meet the eligility criteria and receive 4 Ps. We define communities where all subjects report receiving 4Ps as "complete 4Ps" communities and communities where that is not the case as "incomplete".

${ }^{5}$ Sample communities were selected by DOLE using the following criteria: 1 . Prevalence of child labor as determined by the Philippine Statistics Authority (PSA) using the 2011 Philippine Survey of Children. 2. DOLE intends to target the community for livelihood assistance but has not yet provided any KASAMA. 3. No political opposition, meaning Local Government Units are open to receiving KASAMA as determined by DOLE's regional focal persons. 4. Excluding KASAMA from the community won't constrain DOLE's annual achievements, implying no communities that DOLE is near certifying as child labor free. 5. Logistically feasible to reach the community within the project's budget.

${ }^{6}$ As a part of CLPEP, DOLE categorizes communities as "New Frontier," "Continuing," or "Low Hanging Fruit." In "Low Hanging Fruit" barangays, KASAMA beneficiaries are required to sign a document pledging not to use child labor with the productive asset. In some early documentation, such as our analysis plan, we thought that would be true for our intervention as well. However, subsequent to that writing, we have learned that DOLE does not ask for any such commitment in other barangay classifications. Hence, our beneficiaries have signed no such pledge. Subsequent to our report to DOLE on the findings of this evaluation, they have added this pledge.
} 
the 164 study communities in advance of the baseline survey and before randomization. DOLE maintains lists of households with child labor present from the national targeting system for poverty reduction (Listahanan) and in conjunction with Local Government Units (LGUs). Child laborers that are not household based or in households not known to DOLE are not eligible for KASAMA in either our study or the Philippines in general. Prior to surveying, the research team worked with the LGU to validate the lists provided by DOLE. When more than 14 households were identified, the research team used a simple random number generator to select 14 at random for the evaluation. Only eligible households are interviewed in this evaluation.

DOLE implemented the KASAMA intervention starting in August 2016, four months after the conclusion of the baseline survey. To minimize potential performance bias in survey responses, no parties involved in implementing KASAMA for DOLE were engaged in the collection of data. All data for the evaluation were collected by our independent team of enumerators through IPA Philippines. Survey instructions emphasized that participation in the survey had no bearing on the respondent's receipt of government benefits, and enumerators were reminded in training that if asked, they should confirm that they are from an NGO and are not affiliated with the Government of the Philippines. All enumerators wore IPA polo shirts and carried IPA badges. To reduce expectancy bias, enumerators and other field staff were not told about the partnership with DOLE nor that the survey work was for an evaluation of an intervention aimed to alleviate child labor.

\subsection{Hypotheses}

The theory behind KASAMA is that a one-time productive asset transfer leaves the household wealthier because of the value of the asset and helps them generate future income from the sustained impact of the asset. This in turn eliminates motives for child labor. This theory implies three key hypotheses to test:

- Hypothesis 1: KASAMA has no effect on how the household generates its livelihood. This hypothesis is analogous to a first stage.

- Hypothesis 2: KASAMA does not change the well-being of the household or adolescents in beneficiary households.

- Hypothesis 3: KASAMA does not change the prevalence of child labor. ${ }^{7}$

\footnotetext{
${ }^{7}$ Our AEA registered pre-analysis plan split this hypothesis into two based on the child's baseline time allocation. Based on feedback, we've pushed that detail into heterogeneity and modified hypothesis 3 to not specify the child's baseline time allocation.
} 
In this section, we discuss the evidence that motivates these hypotheses and highlight that KASAMA could increase child labor if households need to draw on family members to convert the asset transfer to income. The outcomes associated with each hypothesis are described in Section 4 below, and precise variable definitions can be found in Appendix 2.

Regarding hypothesis 1 , the related literature spurs us to anticipate finding an increase in household based economic activity if KASAMA is implemented correctly. If capital and factor markets are perfect, KASAMA is similar to a large cash transfer. When family firms are investing optimally, an influx of resources may not change the economic organization of the household. That said, several studies have found that large, one-time cash transfers end up invested in growing or expanding family firms. Most of these studies are targeted at individuals already with a business. De Mel, McKenzie and Woodruff (2008) provide business owners in Sri Lanka the equivalent of $\$ 100$ or $\$ 200$ (depending on the treatment arm) and observe that beneficiaries invest these funds in their businesses and attain real returns of approximately 5 percent per month. Karlan, Knight and Udry (2015) provide tailors in Ghana a cash grant of $\$ 133$ that seems to increase short-term investments.

Our setting differs in at least two important ways. First, not all of our households are entrepreneurs. There is some evidence that even extremely disadvantaged groups invest a cash grant in productive activities. For example, Blattman and Dercon (2016) provide unemployed individuals in Ethiopia a $\$ 300$ cash grant, 55 percent of which was spent on business materials and investments. Haushofer and Shapiro (2016) provide poor Kenyan families $\$ 709$ and observe substantial increases in the value of nonland assets and self employment activities. Second, our transfers are delivered in kind rather than in cash. Many studies of in-kind transfers fix the asset that is transferred, goats for example (Thompson and Magnan, 2017; Banerjee et al., 2018). All published studies of in-kind asset transfers that we know of find an increase in use of that asset. Our asset transfer lies between a cash transfer and most of the in-kind transfers in that our beneficiaries can choose the assets they receive. Given the preponderance of the evidence from both cash and in-kind transfers in a variety of contexts, growth in economic activity related to the transfer should be expected if the transfer is implemented correctly by DOLE.

Regarding hypothesis 2, the value of the asset transfer increases household wealth directly, and the idea behind a one time transfer is that it pushes households into a new situation where they can sustain an increase in living standards. Given the short-term nature of our study, we do not anticipate being able to distinguish between the wealth effect of the resource transfer versus the 
impact of the expansion of the economic activity related to the transfer. Several studies find that one time cash or asset transfers are associated with increases in consumption and other welfare measures (Blattman et al., 2016, Blattman and Dercon, 2016; Haushofer and Shapiro, 2016; Kafle, WinterNelson and Goldsmith, 2016) although that finding is not universal. The ultra-poor graduation programs, which package asset transfers with consumption support in addition to other services, find generally positive impacts on living standards (Haseen, 2006, Das, Misha et al., 2010; Banerjee et al., 2015; Bandiera et al., 2017). We expect improvements in living standards to be measurable with transfer induced increases in family based economic activity.

The primary objective of KASAMA is to reduce child labor, but the existing literature is less clear on what we should anticipate regarding hypothesis 3 . While there is ample evidence in the literature that leads us to anticipate improvements in household economic activity and living standards with KASAMA, very little evidence from the UPG literature, the productive asset transfer literature, and the large cash grant literature is informative about child labor. The few exceptions we are aware of come from UPG evaluations in Bangladesh. While child labor related findings are of secondary interest, the Bangladesh UPG evaluation appears to be novel in that surveys collected proxy respondent information about adolescents. Emran, Robano and Smith (2014) report no effect of a UPG in Bangladesh on child economic activity or years of schooling after 3 years. Bandiera et al. (2017) document that children spend more time in self-employment 4 years after a UPG asset distribution. As the impact of the UPG on adolescents is not their focus, these studies are not designed to replicate the analysis herein and do not directly interview adolescents, measure child labor, or measure child well-being.

This paucity of evidence is unfortunate, because productive asset transfers are currently the dominant tool in efforts to eliminate child labor (like KASAMA, which the Philippine Government considers central in its efforts to combat child labor). While there is ample evidence to suggest that child labor declines with increases in wealth, several studies document that child labor can be higher in the presence of more productive assets in the home, albeit treating endogenous asset endowments as exogenous to local labor markets and family economic histories (Bhalotra and Heady, 2003, Cockburn and Dostie, 2007; Basu, Das and Dutta, 2010; Dumas, 2013). Basu, Das and Dutta (2010) show that much of the confusion in the child labor literature over the wealth elasticity of child labor stems from the fact that when labor and capital markets are imperfect, wealth brings productive opportunities to the household and raises the economic contribution of working children. Dumas (2007) builds on this point and argues that labor market failures are a 
major cause of child labor in Burkina Faso.

When there is disutility of child labor (Basu and Van, 1998), the impact of an increase in child labor's potential economic contribution depends on the marginal utility of consumption that the child's economic contribution brings. In this way, KASAMA can increase child labor in settings where the marginal utility of consumption is very high and labor and capital markets are incomplete. It is not necessarily the case that increases in the shadow value of child labor will increase child labor if, for example, the marginal utility of consumption is low relative to the disutility of child labor (Basu, Das and Dutta, 2010). In that case, the increase in wealth from the asset transfer will lead to a decrease in child labor in the same way it does in the complete markets case (where there is only the wealth effect).

\section{Empirical Analysis}

We use a clustered randomized control trial (RCT) to identify the effect of KASAMA on the primary outcomes outlined in our hypotheses. Using an RCT is suitable to address this research question because it allows us to isolate the role of productive assets in child labor decisions from other factors such as local labor market conditions and family histories that are apt to be correlated with household asset endowments. Randomization was conducted at the community level at DOLE's request because of political and administrative concerns, and after stratifying the population based on 1.) characterization of the community as urban or rural and 2.) whether all respondent households are beneficiaries of the conditional cash transfer 4Ps or not (complete 4Ps vs incomplete 4Ps).

\subsection{Data}

Our data are longitudinal and have been collected over a three year period (2016-2018), principally baseline and endline surveys. The baseline data were collected from February to May 2016. Intervention delivery was conducted by DOLE, beginning in August 2016. The endline survey began in mid February 2018 and finished mid-June 2018. ${ }^{8}$ A midline survey was collected between May 2017 and July 2017. ${ }^{9}$ The midline survey was designed to assist with tracking subjects and to confirm intervention rollout. It is not used in this paper other than to confirm receipt of KASAMA. ${ }^{10}$

\footnotetext{
${ }^{8}$ Data collection was completed after the original Stage 1 submission.

${ }^{9}$ It was not part of the pre-analysis plan. Funding was obtained later.

${ }^{10}$ The Stage 1 submission included a preview of our results using the midline data.
} 


\subsubsection{Data collection and processing}

In each survey round, we conducted a household survey, where we interviewed the household member with the most knowledge of the household's economic activity. This included questions on demographics and detailed time allocation for all household members, assets, consumption, economic activity, government transfers, savings, and food security. During the baseline and endline surveys, we also conducted a child survey of all household members between the ages of $10-17 .{ }^{11}$. This included questions on education, time allocation, work characteristics, life satisfaction, and parenting styles. ${ }^{12}$

To ensure accuracy of the collected data, our enumerators were regularly audited or accompanied by senior field staff, and nightly frequency checks were conducted on the data. $18 \%$ of surveys were audited. $9.2 \%$ of surveys were accompanied with accompanied surveys more prevalent earlier in each survey round. Nightly frequency checks confirmed, among other things, that the household and child surveys are properly matched, consistency in responses across questions, and that values of responses are in the appropriate range. We also conducted 1 week pilots of each of the questionnaires prior to the baseline, midline, and endline surveys to ensure that the questions were properly understood by respondents.

In addition to our survey data, we use household-level administrative records from DOLE on asset distribution and training attendance in our treatment barangays to confirm receipt of treatment, exposure to training, and the type of asset received through the KASAMA program.

\subsubsection{Variations from the intended sample size}

Our sample of 2,296 households includes 14 households in 164 communities. In order to minimize attrition, we asked numerous questions during the baseline and midline surveys to assist with tracking in the follow-up surveys. Social media information proved incredibly useful for tracking.

For our endline survey, we tracked all migrant households and all children who were present at baseline and under 18 at endline regardless of whether they were still associated with the original household. Of the 2,296 households interviewed at baseline, we interviewed 2,288 households at endline for an attrition rate of $0.3 \%$. For children, we interviewed 3,455 children at baseline who are still under age 18 at endline. At endline, we were able to reinterview 3,327 of these children directly for an attrition rate of $3.7 \%$. We have proxy information on 127 of the 128 children we

\footnotetext{
${ }^{11}$ The midline survey was abbreviated and did not interview children

${ }^{12}$ Survey instruments can be found online: https://sites.dartmouth.edu/eedmonds/kasama/.
} 
were unable to interview, implying that full attrition rate (fraction of children for whom we know nothing about their current status) is $0.03 \% .^{13}$

To ensure compliance with treatment assignment, we received quarterly reports from DOLE on asset distribution in our treatment communities and the Philippines overall. This allowed us to monitor that DOLE provided KASAMA to households in our treatment group and also that control barangays were not treated. According to DOLE reports, $94.3 \%$ of treatment households were distributed KASAMA assets, while only one control household received the KASAMA treatment ( $0.09 \%$ of control households). We also use self-reported data from the midline and endline surveys to validate that KASAMA was received by the households that DOLE was supposed to treat and not received in control barangays. Combining data from both the midline and endline surveys, 38 of the 1,148 control households reported receiving KASAMA benefits at some point in either survey. We would be concerned if these were geographically concentrated, but the 38 households are spread across 21 barangays. We think this difference between the household reports and the administrative data is more likely measurement error from the household's perspective, forgetting the name of some social program they received.

\subsection{Power}

The study size was chosen to be able to detect declines in child labor between those assigned to KASAMA and those not in a simple comparison of means although our key hypotheses are about rejecting nulls of no effect of KASAMA. Our ex-ante power calculations suggested that we needed 700 households from 50 communities in order to detect a 10 percent decline in hazardous child labor. This sample was too small for DOLE given their political objectives for the year. Hence, the number of study communities was increased to 164 communities and 2,296 total households. The names and locations of these 2,296 households that make up our baseline sample were provided to us by DOLE using their administrative records of eligible families. ${ }^{14}$

\footnotetext{
${ }^{13}$ The results reported in the main text below use the child's direct responses. We reproduce results where proxy responses are available in Appendix Tables 12 and 13. The full attrition rate is below the household attrition rate, because we were able to complete child surveys for all but 1 of the children in the households we lost.

${ }^{14}$ To determine the minimum detectable effects (MDEs) given our design for our primary outcome variables, we use our baseline data to calculate the means, standard deviations, and the intracluster correlation coefficients of each variable. MDEs for the primary outcomes using the overall sample and by subgroup are shown in Appendix Tables 1-7.
} 


\subsection{Statistical model}

Using a clustered randomized trial to identify the effects of KASAMA on our primary outcomes, we can specify a comparison of means with two sided hypotheses tests in regression form as:

$$
Y_{i, j, k, t}=\beta_{0}+\beta_{1} D_{k}+\pi_{1} S T_{i}+\epsilon_{i t}
$$

where $Y_{i, j, k, t}$ is the outcome for child $i$ in family $j$ associated with community $k$ at time $t$. $D_{k}$ is an indicator that the child lives in a community receiving KASAMA treatment. $S T_{i}$ are stratification fixed effects. ${ }^{15}$ Our analysis focuses largely on $\mathrm{t}=2$, the endline survey. ${ }^{16} \epsilon_{i t}$ is a mean zero error term. When $y$ is child labor, $\beta_{0}$ is mean prevalence of child labor in the control group for the omitted stratum. $\beta_{0}+\beta_{1}$ is mean child labor for children living in households in treatment communities for that stratum.

Baseline data allows us to further reduce variance in (1) and more precisely estimate the impact of KASAMA treatment on our primary outcomes. We control for stratification fixed effects $S T_{i}$, age effects $A_{i, t=0}$, gender $F_{i}$, and baseline values of the outcome variable when available $y_{i, j, k, t=0}$, modifying (1) as:

$$
Y_{i, j, k, t=2}=\beta_{0}+\beta_{1} D_{k}+\pi_{1} S T_{i, k}+\pi_{2} A_{i, t=0}+\pi_{3}\left(A_{i, t=0} * F_{i}\right)+\pi_{4} Y_{i, j, k, t=0}+\epsilon_{k 2}
$$

The inclusion of baseline outcome values implies that we identify the impact of $D$ based on changes in $y$ between the baseline and endline periods. Because we only have complete time allocation for children 10 and above at baseline, we will limit our analysis of time allocation outcomes at endline to children 12 and above. Standard errors are clustered at the community level in all empirical work. We do not have significant issues of non-compliance, and hence our analysis is all a reduced form, intent to treat analysis.

We test the three main hypotheses outlined in Section 2.2 in this study. Because we are interested in the impact of the intervention on adolescents, an observation in all of our confirmatory analysis is a child 12-17. For household level aggregates, this is equivalent to weighting the household's outcomes by the number of children 12-17. To address multiple hypothesis testing, we reduce the number of outcomes by creating indices following Anderson (2008). Each hypothesis has at

\footnotetext{
${ }^{15}$ Stratification fixed effects were not included in this base specification in our pre-analysis plan. We have added these based on feedback during the Stage 1 review process.

${ }^{16}$ In the AEA registered pre-analysis plan, $\mathrm{t}=1$ refers to the endline survey since we did not initially have funding for the midline survey.
} 
most four outcome variables. Any outcome defined as an index is expressed in standard deviations. We also compute FDR-corrected q-values following Benjamini and Hochberg (1995), pooling across all 3 hypotheses.

\subsubsection{Balance}

We use our baseline survey data to evaluate balance across the treatment and control groups prior to the intervention. We test balance on the full sample of resident children 10-17, because the children 10-15 at baseline will be under 17 at endline and thereby the target of our endline analysis and children 16-17 at baseline, though aged out of our endline analysis, provide insights on what the experience of 16 and 17 year olds look like in our communities. ${ }^{17}$ Table 2 shows that the treatment and control groups are balanced across the child, household, and barangay population at baseline, as well as all indices included as primary outcomes. There is not a statistically significant difference between any of the baseline variables. The difference in income between treatment and control appears large in magnitude despite its insignificance. This is driven by an outlier. If we trim the top and bottom 1 percent (as we pre-specify in our approach for outliers in the Stage 1 paper), the difference moves the treatment mean from being more than 70 percent above control to being less than 2 percent below control. Further, even with the outlier included, we fail to reject the null hypothesis that the differences in these characteristics are jointly zero across the treatment and control groups $(\mathrm{F}$-statistic $=0.64)$. Most variables from Table 2 are self explanatory, but those that require construction such as child labor, hazardous child labor, family firm annual income, and per capita monthly expenditures are defined in detail in Appendix 2.

\section{Results}

All empirics behind the analysis in this section were pre-specified in our pre-analysis plan and proposed directly in our JDE Stage 1 review.

\subsection{Economic Organization of the Household}

Table 3 contains the three main confirmatory outcomes relevant to Hypothesis 1 on KASAMA's impact on the economic organization of the household. The dependent variables appear in the rows

\footnotetext{
${ }^{17}$ We also examine balance on the sample of children that we interviewed at baseline and reinterviewed again at endline. The results are shown in Appendix Table 8. There is not a statistically significant difference between any of the baseline variables in the non-attriting sample.
} 
of the table. In columns 1 and 2, an observation is a child present at endline in the household. For columns 3 and 4, an observation is a child interviewed in the child survey at both baseline and endline, the child panel. All other main results tables follow the same set-up. ${ }^{18}$ FDR-correct q-values are included and computed for each specification separately, pooling across all three hypotheses (Tables 3 through 5).

The first outcome in Table 3 is an indicator for whether the household reports receiving KASAMA within the last 12 months in either the midline or the endline survey (thereby fully spanning the implementation window). In Column 2, we find that households in the treatment group are 83.3 percentage points more likely to report receiving the KASAMA program than households in the control group. We restrict the sample to children surveyed both at baseline and endline ("panel children") in Column 3 and include baseline controls as specified in Equation 2 in Column 4.

Given the range of assets distributed under KASAMA, we define a family firm to span agricultural and non-agricultural activities. In the second row of Table 3, Reports Family Firm is an indicator equal to 1 if the household reports an own-income generating activity including nonfarm activities, agriculture, and livestock. 76.1 percent of control households report such a family firm, and we find an increase in reporting a family firm of 9.7 percentage points (12.7 percent) as a result of the KASAMA treatment. With 1,144 treated households recaptured at endline and DOLE's reported compliance rate of $94.3 \%$, these estimates imply that an additional 118 businesses were either started or kept going as a result of KASAMA.

We collected a large volume of questions related to the operation and existence of a household based enterprise including the number of nonfarm enterprises, the number of livestock, the amount of land owned by the household, the number of new enterprises in the last 24 months, income from all family firms (combined), the value of household assets, and the share of adults in family based economic activity. In the third row of Table 3 we report findings of the impact of treatment on a standardized index created across all measures of the presence of family-based economic activity in the household. We find that treatment households experience a 0.19 standard deviation increase in their household based economic activity index relative to control households. We examine the components of this index individually in Appendix Table 10. The increases in the index are driven by increases in the number of nonfarm enterprises and new nonfarm enterprises in treatment

\footnotetext{
${ }^{18}$ In Appendix Table 9, we test the null hypothesis that the sample mean for the full sample of children interviewed at endline is the same as the sample mean for children found at both baseline and endline.
} 
households, as well as higher family firm generated income and a higher share of adults economically active in family based economic activity. The increase in nonfarm activities makes sense given that only 4 percent of assets distributed were in agriculture, reported in Table 1.

\subsection{Well-Being of the Household}

Table 4 contains the four main confirmatory outcomes relevant to Hypothesis 2 on KASAMA's impact on the well-being of household residents. We focus on two outcomes measured at the household level and two at the child level. We observe a positive (5\%) increase in per capita expenditures (includes both food and nonfood items) although we cannot reject the null of no effect on per capita expenditures. ${ }^{19}$

The effects on food security are statistically significant. Food security is measured by a standardized index of household reports of days without food, missing meals, begging, diet composition, and the availability of food in the household. We find a 0.05 standard deviation increase in food security. Figure 1 contains treatment effects on the components of the food security index. The increases in food security seem to be driven by adults not cutting meals, an increase in household members eating preferred foods, and decreases in households borrowing for food or purchasing food on credit. The effects thus appear to be driven by the less severe components of the food security index. This is likely because most of our households were not going without meals prior to treatment. Though very poor, all of our households should be receiving 4Ps which contains consumption support (of course not all households report receiving 4Ps).

There are two child welfare measures pre-specified in our analysis: an index of child schooling and an index on child well-being constructed from several psycho-social questions. The child schooling index is composed of attendance and progression measures. The coefficients are negative in sign but small in magnitude and insignificant. There is social promotion and free schooling in the Philippines, so there is not much scope for the intervention to influence schooling. For child well-being, our index is constructed using measures of child life satisfaction, goal planning, depression, feelings of care from parents, enumerator assessment of social behavior, and caregiver assessment of child strengths and difficulties. These psycho-social measures of child well-being are positively associated with treatment and statistically significant. The positive effects are driven

\footnotetext{
${ }^{19}$ Per capita expenditures are highly variable. We test the robustness of this result to dropping the top and bottom $1 \%$ of values, as specified in our Stage 1 submission for continuous outcomes. Appendix Table 14 shows the results from dropping the top and bottom $1 \%$ of outliers for consumption, which is the only continuous outcome. Outliers do not appear to influence our findings on per capita expenditures.
} 
by increases in life satisfaction as measured by Cantril's ladder and the Student Life Satisfaction Survey (Appendix Table 11).

\subsection{Child Time Allocation}

KASAMA is foremost an anti-child labor intervention. In Table 5 we examine the impact of KASAMA treatment assignment on child labor related outcomes for Hypothesis 3. All of the outcomes in Table 5 are indicator variables. Economic activity in the last 7 days is defined as whether the child has engaged in any productive activity that would fall within the UN SNA definition of economic activity. This may be inside or outside of the household. Child works for pay in the last 7 days indicates if any of that economic activity was for pay. Child is in child labor in the last 12 months is an indicator for whether the child has engaged in any work that would be illegal under Philippine law. Child is in hazardous child labor in the last 12 months is an indicator for whether any of that child labor is in a work situation that would be considered hazardous under Philippine law and ILO Convention C182. We do not find a statistically significant effect of KASAMA on any of these outcome variables. ${ }^{20}$

These child labor results pool children that are in child labor at baseline with those that are not, and the literature on child time allocation generally finds it much more difficult to remove working children from child labor than to prevent children from starting to work. Hence, we examine whether treatment effects vary with child baseline time allocation by estimating Equation 2 separately by whether children are engaged in child labor in the last 12 months at baseline. ${ }^{21}$ Randomization appears valid within each subgroup (Appendix Table 17).

Findings bifurcating the data by baseline child labor status are in Table $6{ }^{22}$ The impact of treatment on KASAMA take-up and the presence of a family business are similar across the two subgroups. Household responses related to Hypothesis 2 are also similar across subgroups. The child well-being results are concentrated in children already in child labor at baseline, with the child well-being coefficients negative and insignificant for children not in child labor at baseline. These children that do not experience the improvements in well-being also work more. Children not in child labor at baseline are 8.3 percentage points more likely to be economically active (Column

\footnotetext{
${ }^{20}$ We have statistical power to detect plausible effects on child labor if the transfer's principal effect were through the wealth transfer intrinsic to the asset. See Appendix 3 for a discussion of minimum detectable effects from the Stage 1 submission.

${ }^{21}$ In our stage 1 submission, we also proposed examining heterogeneity by baseline hazardous child labor status. Because of imbalance in treatment status with that stratification (Appendix Table 18), we do not further explore heterogeneity by baseline hazardous child labor status.

${ }^{22}$ Appendix Table 26 tests the equality of coefficients across the two subgroups.
} 
2), or a 12.5 percent increase in economic activity. These results suggest that for children not in child labor at baseline, the introduction of a family-based enterprise induced them to become economically active.

\subsection{Attrition}

Given that attrition is low and uncorrelated with treatment, it is unlikely a source of bias in our findings. We define attrition of child respondents in three ways:

- Complete attritors, $0.03 \%$. There is one adolescent interviewed at baseline that we know nothing about at endline.

- Attriting migrants, 1.3\%. No child survey and not present in their house at endline. We have proxy responses from family members.

- Non-respondents, 2.4\%. Resident in their household but not interviewed for the child survey. We have proxy responses from family members.

Taken together, this leaves $3.7 \%$ of the sample without direct child survey responses and 1 (treatment) child with no information.

The absence of a direct child survey is not correlated with treatment. A regression of an indicator that we lack a direct child survey at endline on treatment has a coefficient of -0.005 and a standard error of 0.006 . We also find that baseline characteristics are comparable for the children with a completed child survey. The results are shown in Appendix Table 8. There are no statistically significant differences in any of the variables, and the omnibus F-test is also not statistically significant. ${ }^{23}$

\subsection{Heterogeneous effects}

We pre-specified several sub-groups where we thought there would be important differences in the impact of KASAMA. ${ }^{24}$ Our general approach is to estimate Equation 2 separately for each subgroup

\footnotetext{
${ }^{23}$ While bias is not an issue, inference could be affected by attrition through the uncertainty it adds. We have proxy responses about children for all but one of the children that do not complete the child surveys. We cannot measure child well-being, child labor, or hazardous child labor through proxy responses. For children that are present at home but non-responsive, we can calculate all other outcomes. Appendix Table 12 presents these outcomes including proxy responses for children that are in the household but non-respondent. Inference is unaffected. Appendix Table 13 adds in proxy responses for children that are migrants. For all migrants between baseline and endline, we assign household values (such as "Receive KASAMA") based on the outcomes for their household of origin. For child outcomes, we ask questions in the migrant module about what the child is doing in their new location, specifically focusing on schooling, economic activity, and work for pay. Thus, our outcome variables are more limited than for non-respondents. Nonetheless, again there are no substantive changes in inference.

${ }^{24}$ In our AEA registered pre-analysis plan, we specified numerous other margins of heterogeneity that were driven by funder interest. Here, we focus on heterogeneity that contributes to our hypotheses in Section 2.2 In the final report for the funder on the intervention, we explored these other margins of heterogeneity as well.
} 
and to test the equality of $\beta_{1}$ across subgroups. ${ }^{25}$ We also evaluate the validity of randomization within subgroups in a manner consistent with our balance discussion above.

Discussions of adolescent time allocation often emphasize differences by gender and age. Randomization appears valid within each group (we split ages 12-14 and 15-17 as do child labor laws in the Philippines, Appendix Tables 15 and 16). Findings do not vary meaningfully across groups (Appendix Tables 21 and 22), and the data fail to reject the null of no difference between groups (Appendix Tables 24 and 25).

The above sources of heterogeneity vary at the individual level and since the intervention occurred at the barangay level it was thus not possible to design the intervention with those tests of heterogeneity. However, we built two types of heterogeneity into the experiment design. All communities were divided into urban and rural areas. They were also divided into whether all households in our study were receiving the government's support program 4Ps. Interacted, every community was then assigned to one of four stratum and randomization was conducted by the authors within each stratum. Thus, we can test for differences in the effect of KASAMA between urban and rural areas as well as between areas with complete 4Ps and those without.

The decision to stratify by urbanity was driven by there being lots of possible explanations for why the impact of KASAMA would differ by urbanity (including differences in the completeness of markets which could vary with urbanity). Given the design, there should be balance within urban groups, and the data illustrate that (Appendix Table 19). The differences in treatment effects between urban and rural areas are generally small in magnitude and statistically insignificant (Appendix Tables 23 and 27). Given that individuals are free to choose the assets that are best for them in their given situation, it is perhaps not surprising that the impact of choosing what's best for them does not vary with urbanity.

\subsubsection{Correlated Sources of Heterogeneity}

One obvious concern about interpretation of findings with multiple sources of heterogeneity is that those sources of heterogeneity might be correlated with each other or other latent factors. This is especially relevant in our setting where the most important source of heterogeneity, baseline child labor status, is apt to be correlated with age, gender, and urbanity. To evaluate whether our

\footnotetext{
${ }^{25}$ To address the multiple hypotheses issues that arise from these comparisons across subgroups, we compute FDR correct q-values that pool across the different partitions of each type of heterogeneity within a given specification. For example, we provide results using equation (1) for boys and girls separately. Our FDR correct q-values will be computed by combining the p-values from all of the boy and girl results together.
} 
findings of heterogeneity with baseline child labor status reflect factors correlated with age, gender, or urbanity, we include all four sources of heterogeneity together in a single regression. Specifically we modify our estimating equation to:

$$
Y_{i, j, k, t=2}=\beta_{0}+\beta_{1} D_{k}+\Delta D_{k} * H_{i, k}+\Lambda H_{i, k}+\pi_{1} S T_{k}+\pi_{2} A_{i, t=0}+\pi_{3}\left(A_{i, t=0} * F_{i}\right)+\pi_{4} Y_{i, j, k, t=0}+\epsilon_{k 2}
$$

where $\mathrm{H}$ is the vector of sources of heterogeneity discussed above and thus $\Delta$ and $\Lambda$ are vectors of coefficients. These findings are reported in Appendix Table 28. For family based economic activity, child well-being, and child economic activity status we can reject the null of no difference in treatment effects with baseline child labor status. Thus, the distinct results for children that differ in their baseline child labor status do not appear to reflect age, urbanity, gender, or factors closely correlated with those factors. The different treatment effects appear to be because of baseline child labor status, a result we expected based on the child labor literature.

\subsubsection{Households with Consumption Support}

Given the recent research interest in graduation programs and the importance of the asset distribution component of graduation programs (Banerjee et al. 2018), we built into the design of this evaluation the ability to examine the impact of KASAMA on top of consumption support. We pre-specified 4Ps at the community level rather than the household level, because we are concerned about within community selection given that all of our beneficiaries should be receiving 4 Ps. In complete $4 \mathrm{Ps}$ communities, we can evaluate the impact of the asset on our outcomes beyond the other components of $4 \mathrm{Ps}$. We have no explanation for why there are some communities where not all households receive 4Ps. All 4Ps and partial 4Ps communities look similar on measurable characteristics (Appendix Table 20). We suspect measurement error likely drives this distinction, but we cannot be certain. Because of this uncertain variation, we choose not to compare the impact in communities where all households report to those where not all report. ${ }^{26}$ Instead, we just restrict our analysis to the $4 \mathrm{Ps}$ stratum and examine the impact of the productive asset transfer on top of consumption support. In Appendix Table 20, we document balance with respect to the randomization in this stratum.

Our findings for the $4 \mathrm{Ps}$ stratum are in Table 7 . The main difference between our findings

\footnotetext{
${ }^{26}$ For this reason, we have omitted the $4 \mathrm{Ps}$ interactions from our estimates of equation (3).
} 
in the 4 Ps receiving stratum and our earlier results are in the child time allocation results. The increases in child economic activity, work for pay, child labor, and hazardous child labor are larger in magnitude and statistically significant in the stratum where everyone receives consumption support compared to the full sample. In fact, the increases in all of these time allocation measures are at least 3 times the magnitude of the increases in the full sample.

These increases in child labor related measures are consistent with our finding above that treatment induces available labor into work. We observe larger increases in child work with treatment in the 4 Ps stratum, because there are more children available to work in this stratum. Control group children work less at endline in the complete 4Ps stratum (albeit not in a statistically significant way). ${ }^{27}$ Treated children end up working approximately the same amount after treatment in the 4Ps stratum as in the full sample. For example, the child economic activity rates are 7.7 percentage points lower in the complete 4Ps stratum and treatment increases economic activity rates by 8.6 percentage points. This pattern of slightly higher (but not statistically significant) endline participation rates holds in all child labor related outcomes in Table 7. Hence, while treatment increases child time in child labor related measures of time allocation relative to control in the 4Ps stratum, the treated group in the 4Ps stratum does not end up working appreciably more than the overall treated population. Thus, as above, the increase in child labor related outcomes in the 4Ps stratum is consistent with treatment taking up available labor; there is just more available labor in this stratum.

\section{Discussion}

Treatment seems to have been successful in reaching its intended beneficiaries, helping those beneficiaries start or preserve household based enterprises, increasing household based economic activity, and improving food security and child well-being. Direct assessment of child time allocation and child well-being through interviewing children appears novel in this literature (and important as argued in the introduction).

Perhaps the most novel finding is that the intervention seems to induce children who are not in child labor at baseline to start working. This section focuses on understanding this result further. ${ }^{28}$

\footnotetext{
${ }^{27}$ This observation is unlikely to be driven by an effect of 4 Ps on child work. De Hoop et al. (2019) find that 4 Ps increases child work for pay.

${ }^{28}$ All of the results discussed thus far were pre-specified in our Stage 1 paper. In this section, we conduct some exploratory analysis based on the results of our pre-specified analysis. The content of this section has not been pre-specified.
} 
In a setting with complete factor markets, the intervention should not influence whether children work beyond the wealth effect of the transfer, but if the Singh, Squire and Strauss (1986) separation hypothesis does not hold, the influx of capital from treatment can change the (shadow) value of time inside the home. Suppose, for example, that the household cannot hire in labor. Then, the household receiving treatment has two choices: sell or store the asset, or draw on available labor in the household to work the asset to generate income. All published studies that we have seen find that asset transfers lead to use of the asset. Given an opportunity, households try to make the opportunity work. Thus, if the household cannot hire in labor to work the asset (or the previous activities of household members), the asset transfer will draw in available labor.

There is not a lot of available labor in our poor households with child labor present. Our average household has 0.7 members that are not economically active at baseline. These nonworking members have a median age of 15 . Figure 2 plots the average number of individuals in a household in each age group that are not economically active at baseline. Many of these non-working individuals participate in unpaid household services. The non-economically active household members are mainly children, women of childbearing age, and women greater than 50 years of age. Average age of first birth in the Philippines is 23, so that group of non-working 22-30 year olds are likely to have very young children present that may limit the flexibility of their time.

If we directly examine the impact of treatment on economic activity rates for adults by gender and age group, our findings in adults are consistent to what we observed above: treatment increases employment for available labor. Men are almost all working at baseline (Figure 2), and the data are broadly consistent with the hypothesis of no impact of treatment on men (Appendix Table 29). Table 8 contains the results for women of estimating our most basic specification (equation 1). Each cell is from its own regression. Columns indicate age category and rows indicate the subsequent outcome and baseline economic activity status. For women, the largest effect observed in the data comes for women aged 31-40 who are not economically active at baseline. These women will generally be the mothers of the younger children observed in our findings. The coefficient on treatment for not economically active women aged 41-50 is surprisingly negative, but the number of women in that cell is small and findings are imprecise, with 95 percent confidence interval ranging from a 15 percentage point increase in economic activity to a 35 percentage point decline. These increases in economic activity for women aged 31-40 who are not economically active at baseline are predominantly in a family based enterprise.

If our findings on children entering work are driven by the need of a home enterprise to use 
own-household labor, then labor should be especially tight in the approximately $61 \%$ of households reporting a nonfarm enterprise at baseline. They have a lower number of workers available on average (0.5 people) and a lower average age of those available workers (14). Figure 3 mimics Figure 2, restricting the sample to only households that had a nonfarm business at baseline. The result is even more pronounced: there is very little available labor in these households, even less than in the full sample in Figure 2. What little is available is female children, women of child bearing age, and older women.

Above we observed that the impact of the intervention on the extensive margin of child time allocation was concentrated in children that were not already in child labor at baseline. Table 9 contains our findings for the impact of treatment on our primary outcomes for children not in child labor at baseline by whether their household had a nonfarm enterprise present at baseline. ${ }^{29}$ We find increases in family based economic activity in both the nonfarm enterprise and no nonfarm enterprise groups and similar in magnitude increases in the economic activity rates of children (although statistically insignificant). The main distinction across this subgroup is in terms of entry into child labor. Children not in child labor at baseline but in households with a baseline enterprise are 17 percentage points more likely to enter child labor than children in the control group and 22 percentage points more likely to enter hazardous child labor. These increases in hazardous child labor are due to children engaging in more adverse working conditions, such as working with loud noises, handling chemicals, and feeling unwell after working, rather than increased engagement in hazardous occupations such as scavenging (Appendix Figure 1).

There is no statistically significant effect on child labor or hazardous child labor for non-child laborers in households without a nonfarm enterprise at baseline. This suggests that when the household is already engaged in a business, marginal workers such as children engage in more vulnerable types of work. For children engaged in child labor at baseline, we do not find changes in economic activity or child labor status for either the households with nonfarm businesses at baseline or not (Appendix Table 33). These results are consistent with our interpretation about the lack of slack labor: when little labor is available in the household, in this case associated with a pre-existing business, more vulnerable workers engage in work, and perhaps less desirable work as observed with the hazardous work result. In these same households where child labor is increasing amongst those not engaged at baseline, we do not see the improvements in child life satisfaction

\footnotetext{
${ }^{29}$ Appendix Table 30 shows the test for balance across the nonfarm and no nonfarm enterprise subgroups. Appendix Table 31 shows the results by these subgroups for all children, not just non-child laborers. Appendix Table 32 includes controls for the two imbalance variables in Appendix Table 30.
} 
that we observe in the general population..$^{30}$

\section{Conclusion}

Overall, KASAMA reached its targeted population, and these households opened, maintained, and expanded enterprises. It is worth emphasizing that the enterprises opened or expanded through KASAMA are not necessarily directly using the assets transferred through KASAMA. In our qualitative work, we encountered many subjects who received assets in one business and then bought and sold several times to find the business that worked best. Qualitative respondents reported little value in the training sessions, and also were unaware that the transfer was targeted at households with child laborers. Hence, we are confident that the impacts we are measuring in this study come through how beneficiaries interact with the asset transfer itself.

These achievements from KASAMA improved the material well-being of some of the poorest households in the Philippines. However, KASAMA does not appear to have substantively reduced child labor in beneficiary households, as was its stated goal. In fact, in many households, children who were not in child labor at baseline were drawn into economic activity.

This highlights one of the important tensions in using a sustainable livelihood program to combat child labor. Families with child labor present are amongst the poorest and most disadvantaged, and livelihood support can ameliorate their poverty (as KASAMA has done). However, when introducing a new economic activity into a household, available labor is needed to work in the new economic activity. In the case of the Philippines, there was no evidence of a large surplus of prime age adult labor. Poor families are working hard to make ends meet, so the addition of a new economic activity or expanding an existing activity will necessarily bring in more marginal workers. Thus, it is critical to be clear on the goals of a sustainable livelihood program. If the goal is to improve the lives of families with child labor, then KASAMA was an impressive success. If the goal was to eliminate child labor in beneficiary families, then these findings will be disappointing.

These contrasting goals are particularly evident when we look at the impact of KASAMA in families with a nonagricultural family business present at baseline. These experienced entrepreneurs were already using the available labor in their households. In these homes, children did not just work more, they moved into child labor, and though we found improvements in living standards

\footnotetext{
${ }^{30}$ One possible explanation for this life satisfaction finding is that the improvements in food security and consumption influence child life satisfaction in the opposite direction of the rise in hazardous work resulting in a negative but insignificant impact of treatment on life satisfaction.
} 
and food security, we did not see the increases in child life satisfaction that we saw in the general population. Thus, children seem to benefit from treatment less in households where there was a pre-existing business.

Efforts to promote household capacity to generate its own livelihood have become the center of many efforts to promote development (from microfinance to graduation programs). Our findings highlight an important issue that needs more attention: not everyone in a family benefits equally from efforts to influence how a household generates its livelihood. The attention in this study has been on labor. Households rely on family members to work their new productive assets, and some of those drawn into work may have weak agency over the time allocation, especially within family based economic activities. Our general findings that households rely on their own family members to work the productive asset and that there is not a lot of available labor in these poor households beyond child labor is consistent with a model of non-separation of household consumption and production decisions which may be appropriate in a wide variety of low income contexts. Hence, our hope is that future studies of efforts to alter how households generate their livelihood will be attentive to how such interventions impact adolescents and other groups that may have limited say within the family.

\section{References}

Anderson, Michael L. 2008. "Multiple inference and gender differences in the effects of early intervention: A reevaluation of the Abecedarian, Perry Preschool, and Early Training Projects." Journal of the American statistical Association, 103(484): 1481-1495.

Bandiera, Oriana, Robin Burgess, Narayan Das, Selim Gulesci, Imran Rasul, and Munshi Sulaiman. 2017. "Labor markets and poverty in village economies." Quarterly Journal of Economics, 132(2): 811-870.

Banerjee, Abhijit, Dean Karlan, Robert Darko Osei, Hannah Trachtman, and Christopher Udry. 2018. "Unpacking a multi-faceted program to build sustainable income for the very poor." NBER Working Paper 24271.

Banerjee, Abhijit, Esther Duflo, Nathanael Goldberg, Dean Karlan, Robert Osei, William Parienté, Jeremy Shapiro, Bram Thuysbaert, and Christopher Udry. 2015. "A multifaceted program causes lasting progress for the very poor: Evidence from six countries." Science, 348(6236): 1260799 .

Basu, Kaushik, and Pham Hoang Van. 1998. "The economics of child labor." American Economic Review, 88(3): 412-427.

Basu, Kaushik, Sanghamitra Das, and Bhaskar Dutta. 2010. "Child labor and household wealth: Theory and empirical evidence of an inverted-U." Journal of Development Economics, 91(1): 8-14. 
Benjamini, Yoav, and Yosef Hochberg. 1995. "Controlling the false discovery rate: a practical and powerful approach to multiple testing." Journal of the royal statistical society. Series B (Methodological), 289-300.

Bhalotra, Sonia, and Christopher Heady. 2003. "Child farm labor: The wealth paradox." The World Bank Economic Review, 17(2): 197-227.

Blattman, Christopher, and Stefan Dercon. 2016. "Occupational choice in early industrializing societies: Experimental evidence on the income and health effects of industrial and entrepreneurial work." NBER Working Paper 22683.

Blattman, Christopher, Eric P Green, Julian Jamison, M Christian Lehmann, and Jeannie Annan. 2016. "The returns to microenterprise support among the Ultrapoor: A field experiment in Postwar Uganda." American Economic Journal: Applied Economics, 8(2): 35-64.

Blattman, Christopher, Nathan Fiala, and Sebastian Martinez. 2013. "Generating skilled self-employment in developing countries: Experimental evidence from Uganda." The Quarterly Journal of Economics, 129(2): 697-752.

Cockburn, John, and Benoit Dostie. 2007. "Child work and schooling: The role of household asset profiles and poverty in rural Ethiopia." Journal of African Economies, 16(4): 519-563.

Das, Narayan C, Farzana A Misha, et al. 2010. "Addressing extreme poverty in a sustainable manner: Evidence from CFPR programme." BRAC CFPR Work. Pap, 19.

De Hoop, Jacobus, Jed Friedman, Eeshani Kandpal, and Furio Rosati. 2019. "Child schooling and child work in the presence of a partial education subsidy." Journal of Human Resources.

De Mel, Suresh, David McKenzie, and Christopher Woodruff. 2008. "Returns to capital in microenterprises: Evidence from a field experiment." The Quarterly Journal of Economics, 123(4): 1329-1372.

Dumas, Christelle. 2007. "Why do parents make their children work? A test of the poverty hypothesis in rural areas of Burkina Faso." Oxford Economic Papers, 59(2): 301-329.

Dumas, Christelle. 2013. "Market imperfections and child labor." World Development, 42: 127142.

Emran, M. Shahe, Virginia Robano, and Stephen C. Smith. 2014. "Assessing the grontiers of ultrapoverty reduction: Evidence from challenging the frontiers of poverty reduction/targeting the ultra-poor, an innovative program in Bangladesh." Economic Development and Cultural Change, 62(2): 339-380.

Haseen, Farhana. 2006. "Change in food and nutrient consumption among the ultra poor: Is the CFPR/TUP programme making a difference?" BRAC CFPR Work. Pap.

Haushofer, Johannes, and Jeremy Shapiro. 2016. "The short-term impact of unconditional cash transfers to the poor: Experimental evidence from Kenya." The Quarterly Journal of Economics, 131(4): 1973-2042.

Kafle, Kashi, Alex Winter-Nelson, and Peter Goldsmith. 2016. "Does 25 cents more per day make a difference? The impact of livestock transfer and development in rural Zambia." Food Policy, 63: 62-72. 
Karlan, Dean, Ryan Knight, and Christopher Udry. 2015. "Consulting and capital experiments with microenterprise tailors in Ghana." Journal of Economic Behavior \& Organization, 118: $281-302$.

LaFave, Daniel, and Duncan Thomas. 2016. "Farms, families, and markets: New evidence on completeness of markets in agricultural settings." Econometrica, 84(5): 1917-1960.

LaFave, Daniel, Evan Peet, and Duncan Thomas. 2017. "Who behaves as if rural markets are complete?"

Singh, Inderjit, Lyn Squire, and John Strauss. 1986. Agricultural household models: Extensions, applications, and policy. The World Bank.

Thompson, William M, and Nicholas Magnan. 2017. "Predicting Success in a Productive Asset Transfer Program: A Goat Program in Haiti." Applied Economic Perspectives and Policy, 39(2): 363-385. 
Figure 1: Effects on Components of Food Security Index

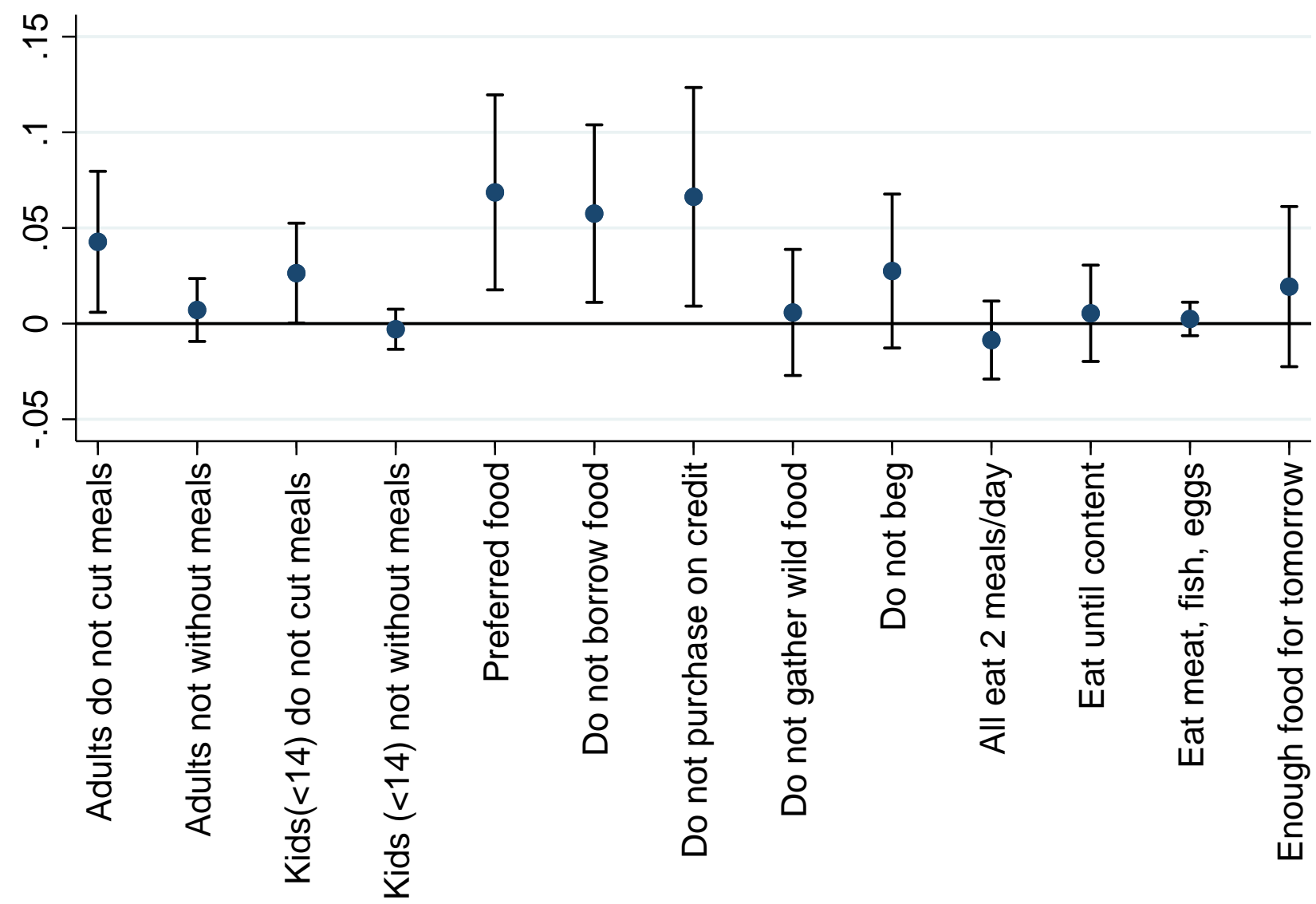

Notes: Each point plots the treatment effect on a component of the food security index with $95 \%$ confidence intervals. An observation is a child 12-17, and outcomes are assigned based on the household the child was assigned to at baseline. The sample includes all children interviewed at endline. All specifications include stratum fixed effects, which are dummies indicating which of the four strata that the child's household of residence resided in at baseline. Standard errors are clustered on the unit of randomization (barangay) throughout. 
Figure 2: Average Number of Household Members Not Economically Active at Baseline

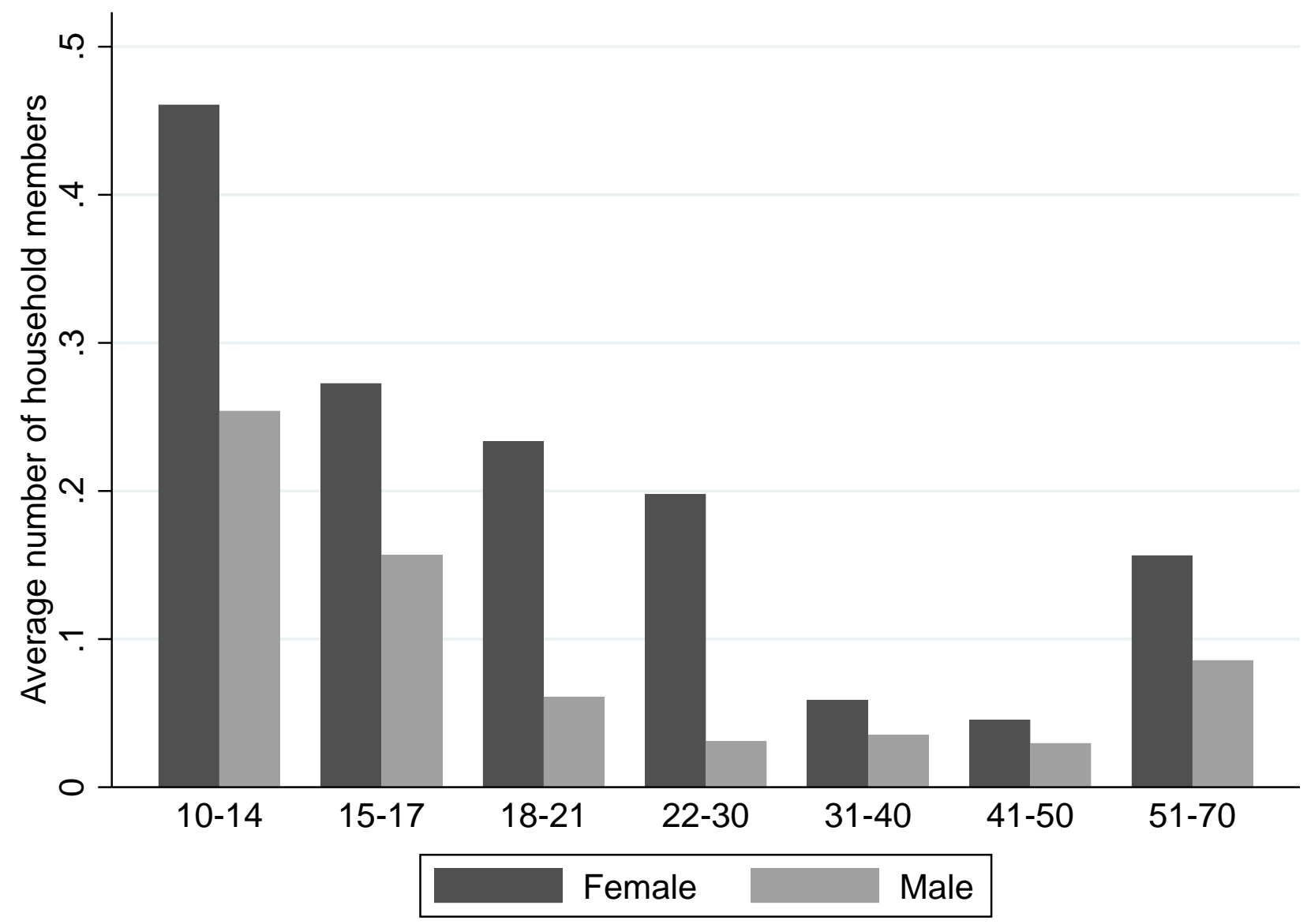

Notes: Each bar shows the average number of household members in a given age and gender group that are not economically active at baseline. 
Figure 3: Average Number of Household Members Not Economically Active at Baseline in Baseline Nonfarm Enterprise Households

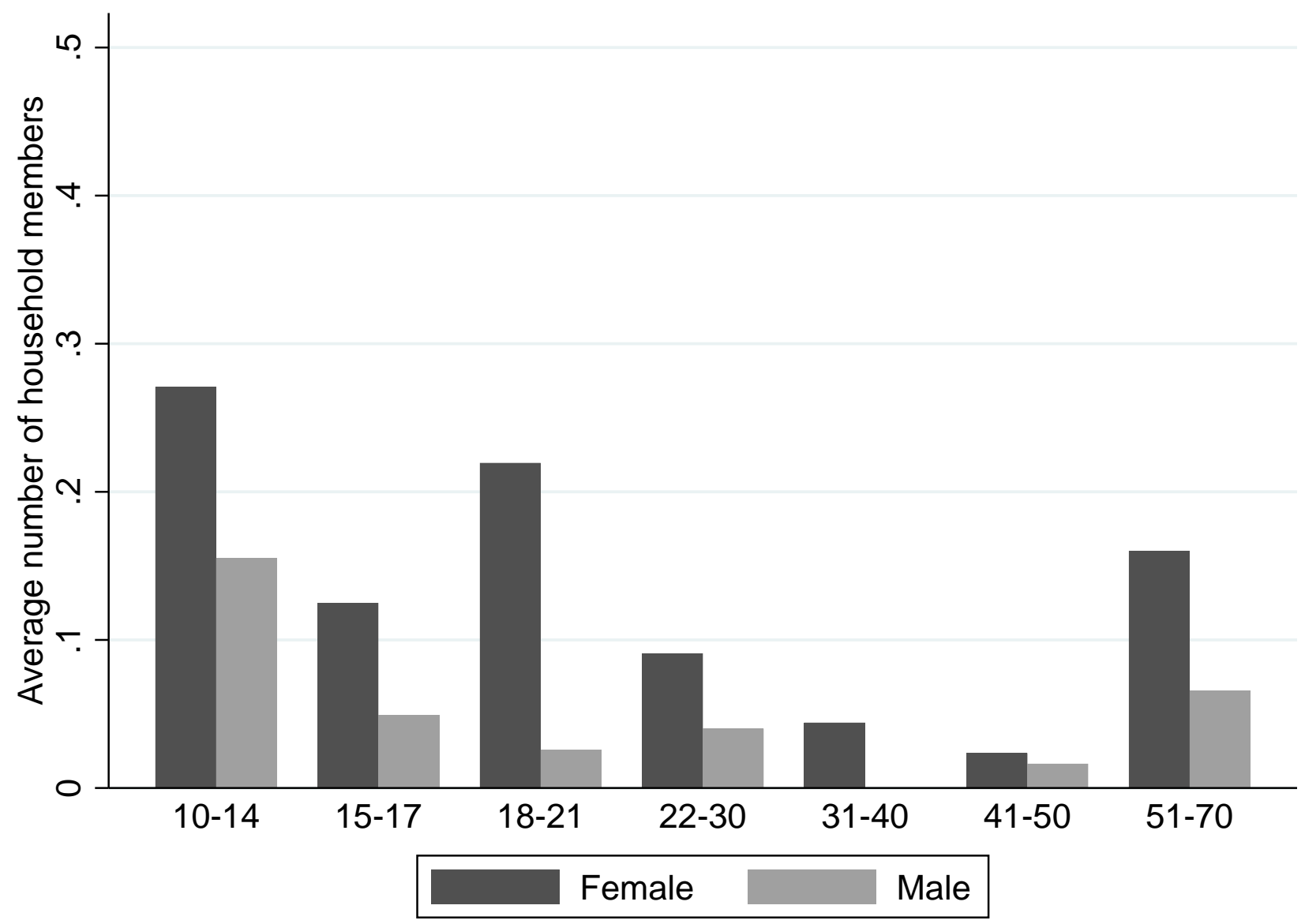

Notes: Each bar shows the average number of household members in a given age and gender group that are not economically active at baseline and are in households with a nonfarm enterprise at baseline. 
Table 1. Distribution of KASAMA Assets

\begin{tabular}{lc}
\hline Asset Type & Percent of Total \\
\hline Rice and Food Vending & 37 \\
Sari-Sari Store & 33 \\
Fishing & 6 \\
Livestock & 2 \\
Other Farming & 2 \\
Sewing and Tailoring & 2 \\
Welding and Carpentry & 2 \\
Other Tools and Equipment & 15 \\
NEC & 1 \\
\hline
\end{tabular}

Notes: Distribution of KASAMA assets from DOLE's official records on KASAMA asset dispersement. 
Table 2. Balance of Baseline Variables

\begin{tabular}{|c|c|c|c|}
\hline Variable & Treatment Mean & Control Mean & Difference \\
\hline \multirow[t]{2}{*}{ Age of child } & 13.32 & 13.26 & 0.06 \\
\hline & $(2.18)$ & (2.22) & $(0.06)$ \\
\hline \multirow[t]{2}{*}{ Child is female } & 0.46 & 0.47 & -0.00 \\
\hline & $(0.50)$ & $(0.50)$ & $(0.01)$ \\
\hline \multirow[t]{2}{*}{ School attendance rate of child over last 7 days } & 0.47 & 0.45 & 0.02 \\
\hline & $(0.46)$ & $(0.46)$ & $(0.05)$ \\
\hline \multirow[t]{2}{*}{ Child is grade(s) behind } & 0.04 & 0.04 & -0.00 \\
\hline & $(0.19)$ & $(0.19)$ & $(0.01)$ \\
\hline \multirow[t]{2}{*}{ Child is economically active in last 7 days } & 0.84 & 0.81 & 0.03 \\
\hline & $(0.37)$ & $(0.39)$ & $(0.02)$ \\
\hline \multirow[t]{2}{*}{ Child is in child labor in last 12 months } & 0.73 & 0.74 & -0.01 \\
\hline & $(0.44)$ & $(0.44)$ & $(0.02)$ \\
\hline \multirow[t]{2}{*}{ Child is in hazardous employment in last 12 months } & 0.44 & 0.45 & -0.01 \\
\hline & $(0.50)$ & $(0.50)$ & $(0.03)$ \\
\hline \multirow[t]{2}{*}{ Child works for pay in last 7 days } & 0.15 & 0.16 & -0.01 \\
\hline & $(0.36)$ & $(0.37)$ & $(0.02)$ \\
\hline \multirow[t]{2}{*}{ Respondent is female } & 0.81 & 0.82 & -0.01 \\
\hline & $(0.39)$ & $(0.39)$ & $(0.02)$ \\
\hline \multirow[t]{2}{*}{ Household size } & 6.78 & 6.93 & -0.15 \\
\hline & $(2.21)$ & $(2.28)$ & $(0.15)$ \\
\hline \multirow[t]{2}{*}{ Number of children in household } & 3.86 & 3.97 & -0.11 \\
\hline & $(1.63)$ & $(1.78)$ & $(0.12)$ \\
\hline \multirow[t]{2}{*}{ Household receives other government transfers in last 12 months } & 0.07 & 0.07 & 0.00 \\
\hline & $(0.25)$ & $(0.25)$ & $(0.01)$ \\
\hline \multirow[t]{2}{*}{ Household reports family firm in last 12 months } & 0.63 & 0.61 & 0.02 \\
\hline & $(0.48)$ & $(0.49)$ & $(0.04)$ \\
\hline \multirow[t]{2}{*}{ Family firm generated income in last 12 months (PPP adjusted) } & 662.55 & 384.73 & 277.82 \\
\hline & $(3297.35)$ & $(15217.87)$ & $(386.84)$ \\
\hline \multirow[t]{2}{*}{ Food expenditure as a share of non-durable expenditure in past 30 days } & 0.64 & 0.64 & -0.00 \\
\hline & $(0.15)$ & $(0.15)$ & $(0.01)$ \\
\hline \multirow[t]{2}{*}{ In(Total monthly household expenditure per capita) } & 4.30 & 4.29 & 0.01 \\
\hline & $(0.55)$ & $(0.61)$ & $(0.04)$ \\
\hline \multirow[t]{2}{*}{ Household has savings } & 0.34 & 0.34 & 0.00 \\
\hline & $(0.47)$ & $(0.47)$ & $(0.03)$ \\
\hline \multirow[t]{2}{*}{ Household has loans } & 0.78 & 0.78 & 0.01 \\
\hline & $(0.41)$ & $(0.42)$ & $(0.02)$ \\
\hline \multirow[t]{2}{*}{ Household had a shock in last 12 months } & 0.64 & 0.65 & -0.01 \\
\hline & $(0.48)$ & $(0.48)$ & $(0.03)$ \\
\hline Household had an illness in past 30 days & 0.20 & 0.19 & 0.01 \\
\hline & $(0.40)$ & $(0.39)$ & $(0.02)$ \\
\hline Household has outmigrants in last 24 months & 0.17 & 0.19 & -0.02 \\
\hline & $(0.38)$ & $(0.39)$ & $(0.02)$ \\
\hline Barangay population (2010 Census) & 3675.69 & 3428.73 & 246.95 \\
\hline & $(3567.77)$ & $(3777.18)$ & $(574.64)$ \\
\hline Family Economic Activity Index & 0.03 & -0.00 & 0.03 \\
\hline & $(0.37)$ & $(0.40)$ & $(0.02)$ \\
\hline Food Security Index & -0.03 & -0.02 & -0.01 \\
\hline & $(0.44)$ & $(0.46)$ & $(0.03)$ \\
\hline Schooling Index & 0.01 & 0.00 & 0.01 \\
\hline & $(0.63)$ & $(0.65)$ & $(0.04)$ \\
\hline Child Well-Being Index & -0.03 & 0.00 & -0.03 \\
\hline & $(0.68)$ & $(0.66)$ & $(0.03)$ \\
\hline Observations & 2,156 & 2,148 & 4,304 \\
\hline F-statistic on test of joint significance & & & 0.64 \\
\hline$p$-value on test of joint significance & & & 0.911 \\
\hline
\end{tabular}

Notes: The sample includes all children 10-17 interviewed in the baseline child survey. Columns 1 and 2 report the mean of the variable for the treatment and control groups respectively. Column 3 reports the difference (Column 1 - Column 2). Standard errors are in parentheses. The final two rows of the table report the omnibus F-test of the joint significance of all the differences in the column above and the associated p-value. Indices are created following Anderson (2008)'s approach. The standard deviation of an index created is not mechanically 1 because of weighting by the inverse of the covariance matrix in index construction. ${ }^{* \star *} p<0.01,{ }^{* *} p<0.05,{ }^{*} p<0.10$. 
Table 3. Effect of KASAMA on the Economic Organization of the Household (Hypothesis 1)

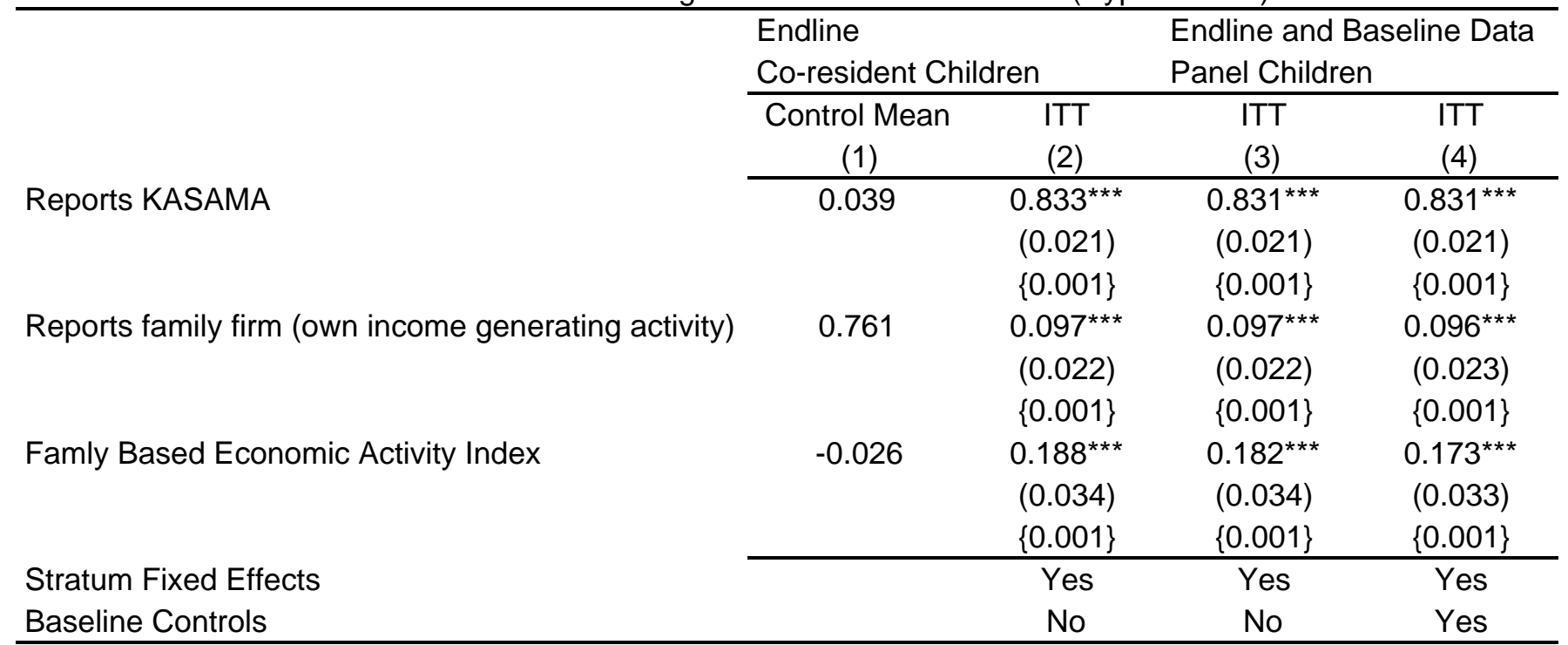

Notes: An observation is a child 12-17. Each outcome is a characteristic of the household the child was

assigned to at baseline. Column 1 contains the mean of the outcome indicated by the row for the control group.

Each cell in columns 2-4 reports the coefficient on an indicator that the child is associated with a household in a community randomly assigned to receive KASAMA. For column 2, this means the child at endline is living in a household that at baseline was in a community that was assigned treatment. For columns 3 and 4, this means that the child at baseline resided in a household that at baseline was in a community that was assigned treatment. Stratum fixed effects are dummies indicating which of the four strata that the child's household of residence resided in at baseline. Baseline controls are measured at baseline and include age* ${ }^{*}$ gender fixed effects and the baseline value of the row variable except for "Reports KASAMA" which is not available at baseline. Standard errors in parenthesis and clustered on unit of randomization throughout (Barangay). FDR corrected q-values in brackets following Benjamini and Hochberg (1995); all coefficients with the same specification (e.g. column 2, 3, or 4) across tables 3, 4, and 5 are grouped for calculation of q-values. The standard deviation of an index created using Anderson (2008)'s approach is not mechanically 1 because of weighting by the inverse of the covariance matrix in index construction. 
Table 4. Effect of KASAMA on the Well-Being of Household Residents (Hypothesis 2)

\begin{tabular}{|c|c|c|c|c|}
\hline & \multicolumn{2}{|c|}{$\begin{array}{l}\text { Endline } \\
\text { Co-resident Children }\end{array}$} & \multicolumn{2}{|c|}{$\begin{array}{l}\text { Endline and Baseline Data } \\
\text { Panel Children }\end{array}$} \\
\hline & Control Mean & ITT & ITT & ITT \\
\hline & $(1)$ & $(2)$ & (3) & $(4)$ \\
\hline \multirow[t]{3}{*}{ In(PPP Adjusted USD Household Monthly Per Capita Expenditure) } & 4.413 & 0.047 & 0.046 & 0.043 \\
\hline & & $(0.033)$ & $(0.034)$ & $(0.029)$ \\
\hline & & $\{0.297\}$ & $\{0.321\}$ & $\{0.251\}$ \\
\hline \multirow[t]{3}{*}{ Food Security Index } & -0.017 & $0.046^{*}$ & $0.051^{* *}$ & $0.056^{\star *}$ \\
\hline & & $(0.027)$ & $(0.026)$ & $(0.023)$ \\
\hline & & $\{0.191\}$ & $\{0.110\}$ & $\{0.039\}$ \\
\hline \multirow[t]{3}{*}{ Child Schooling Index } & 0.055 & -0.010 & -0.010 & -0.014 \\
\hline & & $(0.021)$ & $(0.021)$ & $(0.020)$ \\
\hline & & $\{0.637\}$ & $\{0.700\}$ & $\{0.543\}$ \\
\hline \multirow[t]{3}{*}{ Child Well Being Index } & 0.014 & $0.038^{* * *}$ & $0.031^{* *}$ & $0.034^{* *}$ \\
\hline & & $(0.014)$ & $(0.014)$ & $(0.014)$ \\
\hline & & $\{0.018\}$ & $\{0.084\}$ & $\{0.039\}$ \\
\hline Stratum Fixed Effects & & Yes & Yes & Yes \\
\hline Baseline Controls & & No & No & Yes \\
\hline
\end{tabular}

Notes: An observation is a child 12-17. Household PCX and Food Security Index are characteristics of the household the child was assigned to at baseline. Column 1 contains the mean of the outcome indicated by the row for the control group. Each cell in columns 2-4 reports the coefficient on an indicator that the child is associated with a household in a community randomly assigned to receive KASAMA. For column 2, this means the child at endline is living in a household that at baseline was in a community that was assigned treatment. For columns 3 and 4, this means that the child at baseline resided in a household that at baseline was in a community that was assigned treatment. Stratum fixed effects are dummies indicating which of the four strata that the child's household of residence resided in at baseline. Baseline controls are measured at baseline and include age*gender fixed effects and baseline values of the dependent variable. Standard errors in parenthesis and clustered on unit of randomization throughout (Barangay). FDR corrected q-values in brackets following Benjamini and Hochberg (1995); all coefficients with the same specification (e.g. column 2, 3, or 4) across tables 3, 4, and 5 are grouped for calculation of q-values. The standard deviation of an index created using Anderson (2008)'s approach is not mechanically 1 because of weighting by the inverse of the covariance matrix in index construction. 
Table 5. Effect of KASAMA on Child Labor Related Outcomes (Hypothesis 3)

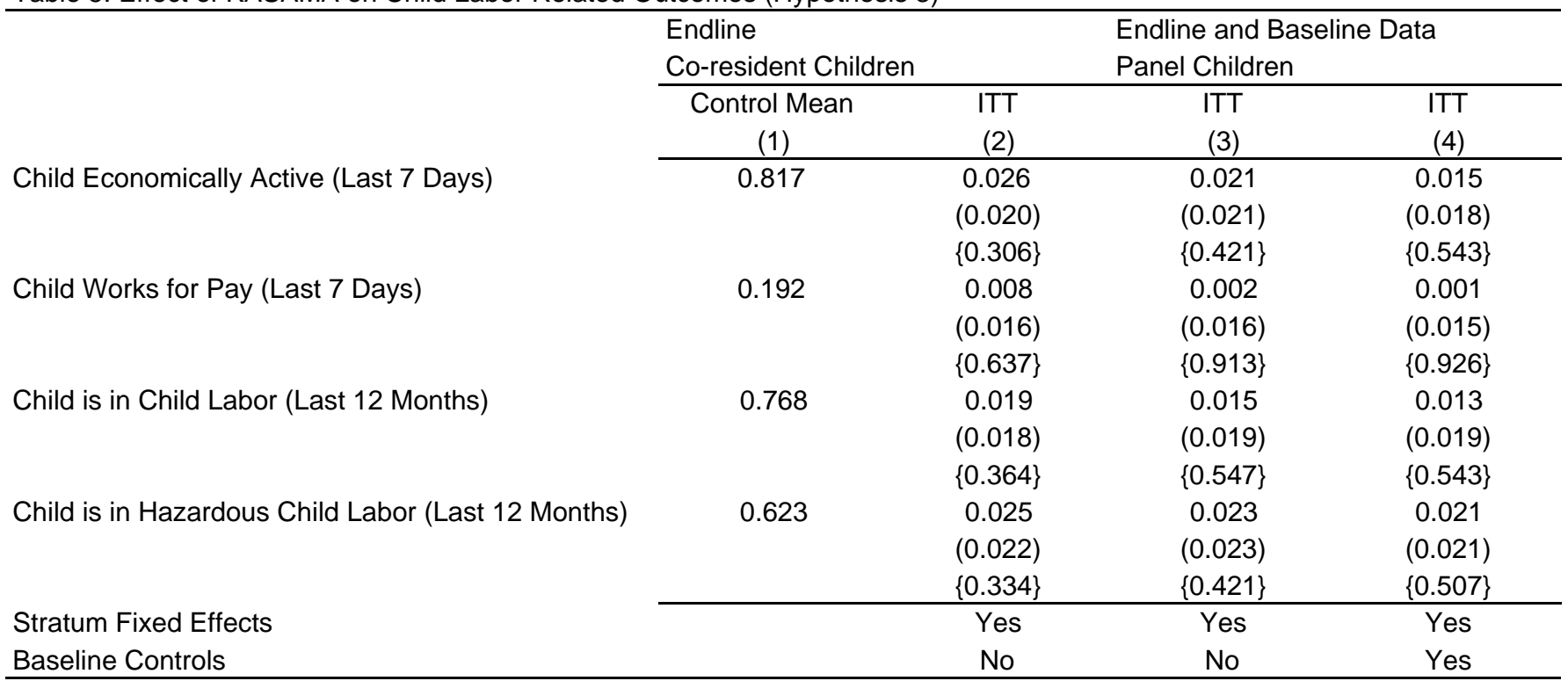

Notes: An observation is a child 12-17. Column 1 contains the mean of the outcome indicated by the row for the control group. Each cell in columns 2-4 reports the coefficient on an indicator that the child is associated with a household in a community randomly assigned to receive KASAMA. For column 2, this means the child at endline is living in a household that at baseline was in a community that was assigned treatment. For columns 3 and 4 , this means that the child at baseline resided in a household that at baseline was in a community that was assigned treatment. Stratum fixed effects are dummies indicating which of the four strata that the child's household of residence resided in at baseline. Baseline controls are measured at baseline and include age*gender fixed effects and baseline values of the dependent variable. Standard errors in parenthesis and clustered on unit of randomization throughout (Barangay). FDR corrected q-values in brackets following Benjamini and Hochberg (1995); all coefficients with the same specification (e.g. column 2, 3, or 4) across tables 3 , 4, and 5 are grouped for calculation of q-values. The standard deviation of an index created using Anderson (2008)'s approach is not mechanically 1 because of weighting by the inverse of the covariance matrix in index construction. 
Table 6. Effect of KASAMA by Baseline Child Labor Status

Reports KASAMA

Reports family firm (own income generating activity)

Not in Child Labor

Panel Children

In Child Labor

\begin{tabular}{lcccc} 
Co-resident Children & Panel Children & & Co-resident Child \\
\hline Control Mean & ITT & ITT & ITT & Control Mean \\
& & $(3)$ & (4) & $(5)$
\end{tabular}

hildren

Panel Children

\begin{tabular}{|c|c|c|c|c|c|c|c|}
\hline $\begin{array}{l}\text { Control Mean } \\
\text { (1) }\end{array}$ & $\begin{array}{l}\text { ITT } \\
(2)\end{array}$ & $\begin{array}{l}\text { ITT } \\
(3)\end{array}$ & $\begin{array}{l}\text { ITT } \\
(4)\end{array}$ & $\begin{array}{c}\text { Control Mean } \\
\text { (5) }\end{array}$ & $\begin{array}{l}\text { ITT } \\
(6)\end{array}$ & $\begin{array}{l}\text { ITT } \\
(7)\end{array}$ & $\begin{array}{l}\text { ITT } \\
(8)\end{array}$ \\
\hline \multirow[t]{3}{*}{0.043} & $0.799^{\star \star \star}$ & $0.799^{\star \star \star}$ & $0.800^{\star \star \star}$ & 0.039 & $0.844^{\star \star \star}$ & $0.844^{\star \star \star}$ & $0.844^{\star \star \star}$ \\
\hline & (0.029) & $(0.029)$ & $(0.029)$ & & $(0.021)$ & $(0.021)$ & $(0.021)$ \\
\hline & $\{0.001\}$ & $\{0.001\}$ & $\{0.001\}$ & & $\{0.001\}$ & $\{0.001\}$ & $\{0.001\}$ \\
\hline \multirow[t]{3}{*}{0.707} & $0.119^{\star * *}$ & $0.119^{\star * *}$ & $0.114^{\star \star *}$ & 0.779 & $0.090^{\star \star *}$ & $0.090^{\star \star \star}$ & $0.091^{\star \star \star}$ \\
\hline & $(0.036)$ & $(0.036)$ & $(0.037)$ & & $(0.023)$ & $(0.023)$ & $(0.024)$ \\
\hline & $\{0.005\}$ & $\{0.005\}$ & $\{0.009\}$ & & $\{0.001\}$ & $\{0.001\}$ & $\{0.001\}$ \\
\hline \multirow[t]{3}{*}{-0.162} & $0.283^{* \star *}$ & $0.283^{* * *}$ & $0.272^{\star \star \star *}$ & 0.026 & $0.152^{\star \star \star}$ & $0.152^{\star \star \star}$ & $0.145^{\star \star \star}$ \\
\hline & $(0.059)$ & $(0.059)$ & $(0.056)$ & & $(0.031)$ & $(0.031)$ & $(0.031)$ \\
\hline & $\{0.001\}$ & $\{0.001\}$ & $\{0.001\}$ & & $\{0.001\}$ & $\{0.001\}$ & $\{0.001\}$ \\
\hline \multirow[t]{3}{*}{4.492} & $0.081^{*}$ & $0.081^{*}$ & $0.090^{\star \star}$ & 4.404 & 0.032 & 0.032 & 0.026 \\
\hline & $(0.048)$ & $(0.048)$ & $(0.042)$ & & $(0.037)$ & $(0.037)$ & $(0.033)$ \\
\hline & $\{0.199\}$ & $\{0.199\}$ & $\{0.085\}$ & & $\{0.614\}$ & $\{0.614\}$ & $\{0.631\}$ \\
\hline \multirow[t]{3}{*}{-0.017} & $0.080^{\star *}$ & $0.080^{\star \star}$ & $0.090^{\star *}$ & -0.018 & 0.040 & 0.040 & 0.043 \\
\hline & $(0.036)$ & $(0.036)$ & (0.036) & & $(0.028)$ & $(0.028)$ & $(0.026)$ \\
\hline & $\{0.082\}$ & $\{0.082\}$ & $\{0.038\}$ & & $\{0.317\}$ & $\{0.317\}$ & $\{0.201\}$ \\
\hline \multirow[t]{3}{*}{0.010} & -0.024 & -0.024 & -0.027 & 0.062 & -0.004 & -0.004 & -0.008 \\
\hline & (0.031) & $(0.031)$ & (0.029) & & $(0.023)$ & $(0.023)$ & $(0.022)$ \\
\hline & $\{0.614\}$ & $\{0.614\}$ & $\{0.574\}$ & & $\{0.925\}$ & $\{0.925\}$ & $\{0.853\}$ \\
\hline \multirow[t]{3}{*}{0.074} & -0.005 & -0.005 & -0.006 & 0.002 & $0.043^{\star \star \star}$ & $0.043^{\star \star \star}$ & $0.047^{\star \star \star}$ \\
\hline & $(0.025)$ & $(0.025)$ & $(0.024)$ & & $(0.016)$ & $(0.016)$ & $(0.016)$ \\
\hline & $\{0.925\}$ & $\{0.925\}$ & $\{0.927\}$ & & $\{0.021\}$ & $\{0.021\}$ & $\{0.010\}$ \\
\hline \multirow[t]{3}{*}{0.662} & $0.083^{\star \star}$ & $0.083^{\star \star}$ & $0.068^{\star}$ & 0.874 & 0.002 & 0.002 & -0.001 \\
\hline & $(0.039)$ & (0.039) & $(0.036)$ & & $(0.017)$ & $(0.017)$ & $(0.017)$ \\
\hline & $\{0.093\}$ & $\{0.093\}$ & $\{0.123\}$ & & $\{0.925\}$ & $\{0.925\}$ & $\{0.957\}$ \\
\hline \multirow[t]{3}{*}{0.118} & 0.007 & 0.007 & 0.001 & 0.217 & 0.002 & 0.002 & 0.002 \\
\hline & (0.022) & $(0.022)$ & $(0.022)$ & & $(0.019)$ & $(0.019)$ & $(0.018)$ \\
\hline & $\{0.925\}$ & $\{0.925\}$ & $\{0.957\}$ & & $\{0.925\}$ & $\{0.925\}$ & $\{0.957\}$ \\
\hline \multirow[t]{3}{*}{0.643} & 0.034 & 0.034 & 0.033 & 0.808 & 0.010 & 0.010 & 0.007 \\
\hline & $(0.037)$ & $(0.037)$ & $(0.037)$ & & $(0.018)$ & $(0.018)$ & $(0.018)$ \\
\hline & $\{0.614\}$ & $\{0.614\}$ & $\{0.574\}$ & & $\{0.775\}$ & $\{0.775\}$ & $\{0.853\}$ \\
\hline \multirow[t]{5}{*}{0.511} & 0.045 & 0.045 & 0.039 & 0.661 & 0.018 & 0.018 & 0.017 \\
\hline & $(0.039)$ & $(0.039)$ & $(0.038)$ & & $(0.024)$ & $(0.024)$ & $(0.023)$ \\
\hline & $\{0.465\}$ & $\{0.465\}$ & $\{0.558\}$ & & $\{0.614\}$ & $\{0.614\}$ & $\{0.651\}$ \\
\hline & Yes & Yes & Yes & & Yes & Yes & Yes \\
\hline & No & No & No & & No & No & No \\
\hline
\end{tabular}

Baseline Controls

No

No

No

No

No

Notes: An observation is a child 12-17. Outcomes are defined as in Tables 3-5. Columns 1 and 5 contain the mean of the outcome indicated by the row for the control group in each

subgroup. Each cell in columns 2-4 and 6-8 reports the coefficient on an indicator that the child is associated with a household in a community randomly assigned to receive KASAMA. For columns 2 and 6 , this means the child at endline is living in a household that at baseline was in a community that was assigned treatment. For columns $3,4,7$, and 8 , this means that the child at baseline resided in a household that at baseline was in a community that was assigned treatment. Stratum fixed effects are dummies indicating which of the four strata that the child's household of residence resided in at baseline. Baseline controls are measured at baseline and include age* ${ }^{*}$ ender fixed effects and the baseline value of the row variable except for "Reports KASAMA" which is not available at baseline. Standard errors in parenthesis and clustered on unit of randomization throughout (Barangay). FDR corrected q-values in brackets following Benjamini and Hochberg (1995); all coefficients with the same specification (e.g. column 2, 3, or 4) across the two subgroups (in child labor at baseline versus not in child labor at baseline) are grouped for calculation of q-values. The standard deviation of an index created using Anderson (2008)'s approach is not mechanically 1 because of weighting by the inverse of the covariance matrix in index construction. 


\section{Reports KASAMA}

Reports family firm (own income generating activity)

Famly Based Economic Activity Index

In(PPP Adjusted USD Household Monthly Per Capita Expenditure)

Food Security Index

Child Schooling Index

. Child Well Being Index

Child Economically Active (Last 7 Days)

Child Works for Pay (Last 7 Days)

Child is in Child Labor (Last 12 Months)

Child is in Hazardous Child Labor (Last 12 Months)

Stratum Fixed Effects

Baseline Controls

Notes: An observation is a child 12-17. Outcomes are defined as in Tables 3-5. Columns 1 and

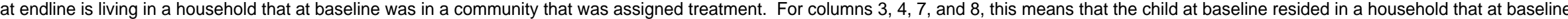

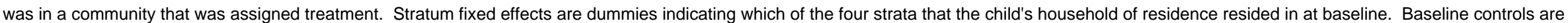

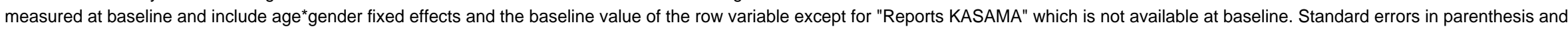
clustered on unit of randomization throughout (Barangay). FDR correct q-values in brackets following Benjamini and Hochberg (1995); all coefficients with the same specification (e.g. column 2, 3, or 4)

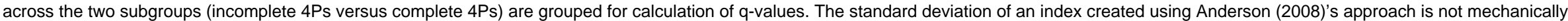
1 because of weighting by the inverse of the covariance matrix in index construction. 
Table 8. Effect of KASAMA on Adult Economic Activity By Age (Females)

\begin{tabular}{|c|c|c|c|c|c|}
\hline & $\begin{array}{c}\text { Ages } 18-21 \\
(1)\end{array}$ & $\begin{array}{c}\text { Ages } 22-30 \\
\text { (2) }\end{array}$ & $\begin{array}{c}\text { Ages } 31-40 \\
\text { (3) }\end{array}$ & $\begin{array}{c}\text { Ages } 41-50 \\
(4)\end{array}$ & $\begin{array}{c}\text { Ages 51-70 } \\
\text { (5) }\end{array}$ \\
\hline \multicolumn{6}{|l|}{ Economic Activity } \\
\hline \multirow[t]{3}{*}{ Females - Pooled } & 0.007 & -0.032 & $0.090^{\star * *}$ & $0.071^{* * *}$ & 0.026 \\
\hline & $(0.039)$ & $(0.044)$ & $(0.026)$ & $(0.021)$ & $(0.032)$ \\
\hline & $\{0.886\}$ & $\{0.622\}$ & $\{0.007\}$ & $\{0.007\}$ & $\{0.622\}$ \\
\hline \multirow[t]{3}{*}{ Females, Economically Active at Baseline } & -0.028 & -0.013 & $0.072^{\star \star \star}$ & $0.080^{\star * *}$ & 0.018 \\
\hline & $(0.042)$ & $(0.052)$ & $(0.024)$ & $(0.021)$ & $(0.025)$ \\
\hline & $\{0.655\}$ & $\{0.861\}$ & $\{0.022\}$ & $\{0.004\}$ & $\{0.622\}$ \\
\hline \multirow[t]{3}{*}{ Females, Not Economically Active at Baseline } & 0.123 & -0.093 & $0.250^{* *}$ & -0.095 & 0.136 \\
\hline & $(0.077)$ & $(0.101)$ & $(0.095)$ & $(0.126)$ & $(0.123)$ \\
\hline & $\{0.339\}$ & $\{0.618\}$ & $\{0.058\}$ & $\{0.622\}$ & $\{0.561\}$ \\
\hline \multicolumn{6}{|l|}{ Works in Family Enterprise } \\
\hline \multirow[t]{3}{*}{ Females - Pooled } & 0.008 & 0.043 & $0.139^{\star \star \star}$ & $0.101^{\star \star *}$ & 0.042 \\
\hline & $(0.037)$ & $(0.044)$ & $(0.034)$ & $(0.030)$ & $(0.037)$ \\
\hline & $\{0.877\}$ & $\{0.610\}$ & $\{0.003\}$ & $\{0.622\}$ & $\{0.560\}$ \\
\hline \multirow[t]{3}{*}{ Females, Economically Active at Baseline } & -0.023 & 0.067 & $0.127^{\star * \star}$ & $0.108^{\star * *}$ & 0.042 \\
\hline & $(0.042)$ & $(0.049)$ & $(0.034)$ & $(0.029)$ & $(0.031)$ \\
\hline & $\{0.717\}$ & $\{0.431\}$ & $\{0.004\}$ & $\{0.007\}$ & $\{0.431\}$ \\
\hline \multirow[t]{3}{*}{ Females, Not Economically Active at Baseline } & 0.115 & -0.035 & $0.241^{* *}$ & -0.041 & 0.091 \\
\hline & $(0.071)$ & $(0.098)$ & $(0.112)$ & $(0.140)$ & $(0.122)$ \\
\hline & $\{0.339\}$ & $\{0.810\}$ & $\{0.166\}$ & $\{0.004\}$ & $\{0.622\}$ \\
\hline \multicolumn{6}{|l|}{ Works Outside Home } \\
\hline \multirow[t]{3}{*}{ Females - Pooled } & -0.015 & $-0.079^{*}$ & -0.039 & -0.032 & -0.005 \\
\hline & $(0.033)$ & $(0.047)$ & $(0.041)$ & $(0.037)$ & $(0.044)$ \\
\hline & $\{0.766\}$ & $\{0.324\}$ & $\{0.610\}$ & $\{0.848\}$ & $\{0.912\}$ \\
\hline \multirow[t]{3}{*}{ Females, Economically Active at Baseline } & -0.032 & -0.075 & -0.063 & -0.043 & -0.021 \\
\hline & $(0.037)$ & $(0.054)$ & $(0.043)$ & $(0.037)$ & $(0.048)$ \\
\hline & $\{0.618\}$ & $\{0.431\}$ & $\{0.405\}$ & $\{0.618\}$ & $\{0.766\}$ \\
\hline \multirow[t]{3}{*}{ Females, Not Economically Active at Baseline } & 0.037 & -0.081 & $0.206^{*}$ & 0.130 & $0.149^{*}$ \\
\hline & $(0.060)$ & $(0.079)$ & $(0.115)$ & $(0.153)$ & $(0.087)$ \\
\hline & $\{0.672\}$ & $\{0.605\}$ & $\{0.322\}$ & $\{0.560\}$ & $\{0.324\}$ \\
\hline
\end{tabular}

Notes: An observation is a female adult aged 18-70. The sample includes all female adults in this age range residing in the household at endline. Each cell represents a separate regression and is the effect of treatment on adult economic activity in the top panel, on working in the family enterprise in the middle panel, and on working outside the home in the bottom panel. Stratum fixed effects, as defined previously, are included in all specifications as dummies. Standard errors in parenthesis and clustered on unit of randomization throughout (Barangay). FDR corrected q-values in brackets following Benjamini and Hochberg (1995) are calculated by pooling all specifications in the table. 
Table 9. Effect of KASAMA by Presence of Baseline Nonfarm Enterprise, No Child Labor

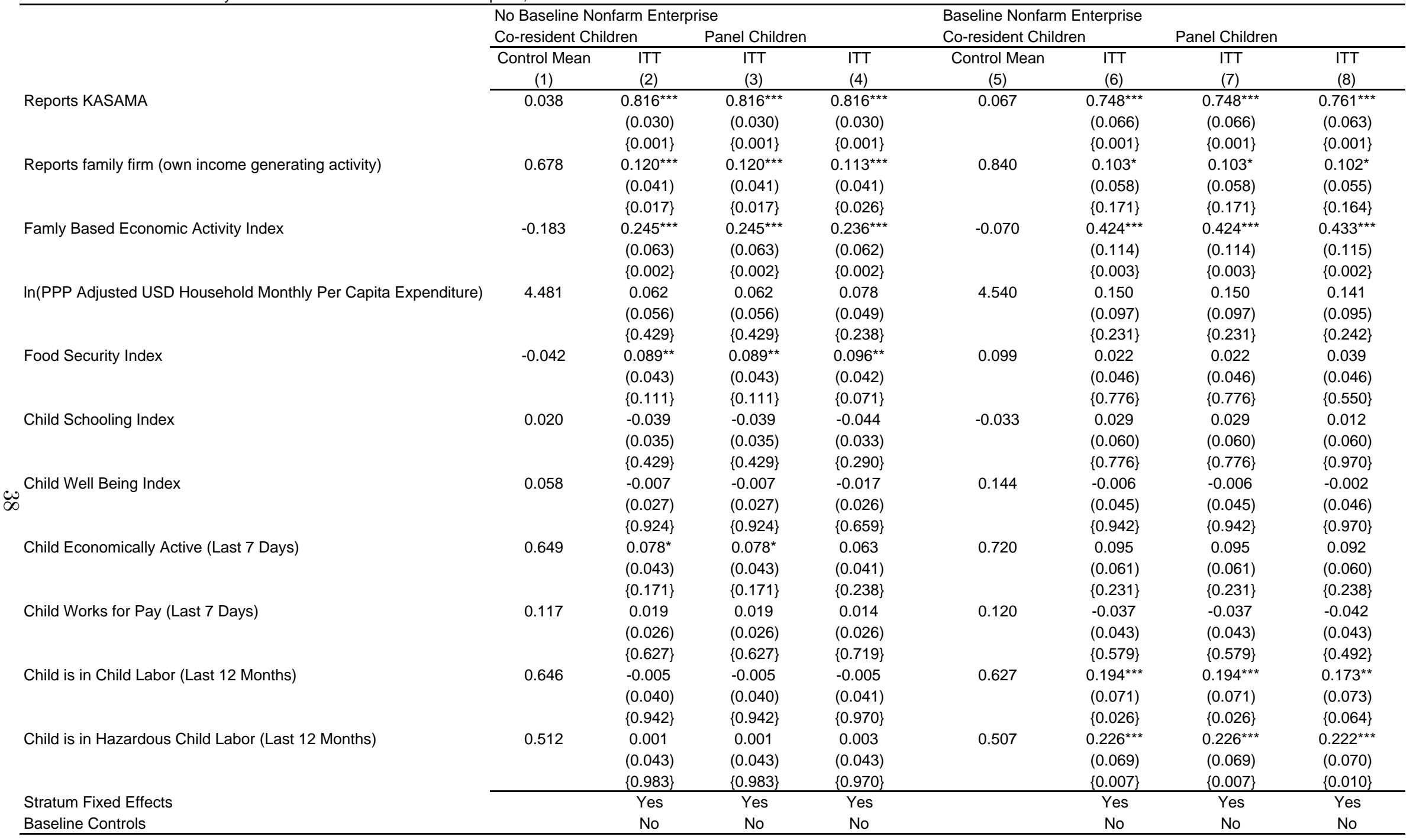

Notes: An observation is a child 12-17. Outcomes are defined as in Tables 3-5. Columns 1 and 5 contain the mean of the outcome indicated by the row for the control group in each subgroup. Each cell in columns 2-4 and 6-8 reports the coefficient on an indicator that the child is associated with a household in a community randomly assigned to receive KASAMA. For columns 2 and 6, this means the child at endline is living in a household that at baseline was in a community that was assigned treatment. For columns $3,4,7$, and 8 , this means that the child at baseline resided in a household that at baseline was in a community that was assigned treatment. Stratum fixed effects are dummies indicating which of the four strata that the child's household of residence resided in at baseline. Baseline controls are measured at baseline and include age* gender fixed effects and the baseline value of the row variable except for "Reports KASAMA" which is not available at baseline. Standard errors in parenthesis and clustered on unit of randomization throughout (Barangay). FDR corrected q-values in brackets following Benjamini and Hochberg (1995); all coefficients with the same specification (e.g. column 2, 3, or 4) across the two subgroups (no baseline nonfarm enterprise versus baseline nonfarm enterprise ) are grouped for calculation of q-values. The standard deviation of an index created using Anderson (2008)'s approach is not mechanically 1 because of weighting by the inverse of the covariance matrix in index construction. 